\title{
Fluoroalkyl and Alkyl Chains Have Similar Hydrophobicities in Binding to the "Hydrophobic Wall" of Carbonic Anhydrase
}

\section{Citation}

Mecinović, Jasmin, Phillip W. Snyder, Katherine A. Mirica, Serena Bai, Eric T. Mack, Richard L. Kwant, Demetri T. Moustakas, Annie Héroux, and George M. Whitesides. 2011. "Fluoroalkyl and Alkyl Chains Have Similar Hydrophobicities in Binding to the 'Hydrophobic Wall' of Carbonic Anhydrase." Journal of the American Chemical Society 133, no. 35: 14017-14026.

\section{Published Version}

doi:10.1021/ja2045293

\section{Permanent link}

http://nrs.harvard.edu/urn-3:HUL.InstRepos:12967814

\section{Terms of Use}

This article was downloaded from Harvard University's DASH repository, and is made available under the terms and conditions applicable to Open Access Policy Articles, as set forth at http:// nrs.harvard.edu/urn-3:HUL.InstRepos:dash.current.terms-of-use\#OAP

\section{Share Your Story}

The Harvard community has made this article openly available.

Please share how this access benefits you. Submit a story.

Accessibility 


\title{
Fluoroalkyl and Alkyl Chains Have Similar
}

\section{Hydrophobicities in Binding to the "Hydrophobic}

\section{Wall' of Carbonic Anhydrase}

\author{
Jasmin Mecinovic, ${ }^{a}$ Phillip W. Snyder, ${ }^{a}$ Katherine A. Mirica, ${ }^{a}$ Serena Bai, ${ }^{a}$ \\ Eric T. Mack, ${ }^{a}$ Richard L. Kwant, ${ }^{a}$ Demetri T. Moustakas, ${ }^{a}$ Annie Heroux, ${ }^{c}$ and George M. \\ Whitesides $^{a, b} *$ \\ ${ }^{a}$ Department of Chemistry and Chemical Biology, Harvard University, \\ 12 Oxford Street, Cambridge, MA 02138 \\ ${ }^{\mathrm{b}}$ Wyss Institute for Biologically Inspired Engineering \\ ${ }^{c}$ National Synchrotron Light Source, Brookhaven National Laboratory, \\ 725 Brookhaven Avenue, Upton, NY 11973-5000
}

* To whom the correspondence should be addressed. Phone: +1 617495 9430. Fax: +1 6174959857. Email: gwhitesides@gmwgroup.harvard.edu 


\section{ABSTRACT}

The hydrophobic effect - the free-energetically favorable association of non-polar solutes in watermakes a dominant contribution to binding of many systems of ligands and proteins. The objective of this study was to examine the hydrophobic effect in biomolecular recognition using two chemically different, but structurally similar hydrophobic groups-aliphatic hydrocarbons and aliphatic fluorocarbons - and to determine whether the hydrophobicity of the two groups could be distinguished by thermodynamic and biostructural analysis. This paper uses isothermal titration calorimetry (ITC) to examine the thermodynamics of binding of benzenesulfonamides substituted in the para position with alkyl and fluoroalkyl chains $\left(\mathrm{H}_{2} \mathrm{NSO}_{2} \mathrm{C}_{6} \mathrm{H}_{4}-\mathrm{CONHCH}_{2}\left(\mathrm{CX}_{2}\right)_{\mathrm{n}} \mathrm{CX}_{3}, \mathrm{n}=0-4, \mathrm{X}=\mathrm{H}, \mathrm{F}\right)$ to human carbonic anhydrase II (HCA II). Both alkyl and fluoroalkyl substituents contribute favorably to the enthalpy and the entropy of binding; these contributions increase as the length of chain of the hydrophobic substituent increases. Crystallography of the protein-ligand complexes indicates that the benzenesulfonamide groups of all ligands examined bind with similar geometry, that the tail groups associate with the hydrophobic wall of HCA II (which is made up of the side chains of residues Phe131, Val135, Pro202, and Leu204), and that the structure of the protein is indistinguishable for all but one of the complexes (the longest member of the fluoroalkyl series). Analysis of the thermodynamics of binding as a function of structure is compatible with the hypothesis that hydrophobic binding of both alkyl and fluoroalkyl chains to hydrophobic surface of carbonic anhydrase is due primarily to the release of non-optimally hydrogen-bonded water molecules that hydrate the binding cavity (including the hydrophobic wall) of HCA II. This study defines the balance of enthalpic and entropic contributions to the hydrophobic effect in this representative system of protein and ligand: hydrophobic interactions, here, seem to comprise approximately equal contributions from enthalpy (plausibly from strengthening networks among molecules of water hydrogen bonds) and entropy (from release of water from configurationally restricted positions). 


\section{Introduction}

\section{Hydrophobic interactions are important for protein-ligand binding, but their molecular basis is}

poorly understood. Hydrophobic interactions - the free energetically favorable aggregation of nonpolar molecules in aqueous media - are centrally important in biology because they dominate the folding of proteins, the formation of lipid bilayers, and the association of proteins and ligands. ${ }^{1-4}$ The classical concept of hydrophobic interactions—-which we attribute to Kauzmann and Tanford (KT)—predicts that i) water near the surface of hydrophobic groups is more (or, perhaps, just differently) structured than bulk water, and ii) entropy dominates the favorable free energy of hydrophobic interactions because association of two non-polar surfaces causes the release of structured molecules of water near non-polar surfaces. ${ }^{1-2}$ The molecular basis of hydrophobic interactions in protein-ligand association is more complicated than this classical description, and still incompletely understood. ${ }^{5-7}$ The distinction between hydrophobic effects when different types of groups-aliphatic and aromatic hydrocarbons, or fluorocarbons-interact within a protein-ligand complex is also not clear. This lack of understanding (probably) contributes to the present difficulty in designing ligands that associate tightly with proteins.

\section{Aliphatic Hydrocarbons and Fluorocarbons in Biomolecular Recognition. Both aliphatic} hydrocarbons $\left(\mathrm{R}_{\mathrm{H}}\right)$ and aliphatic fluorocarbons $\left(\mathrm{R}_{\mathrm{F}}\right)$ are hydrophobic in that they are poorly soluble in water, ${ }^{8}$ but the thermodynamic basis of this hydrophobicity-at least in the context of protein-ligand interactions-is poorly characterized. In drug discovery, replacement of hydrocarbon groups by fluorocarbon groups has been used to modify solubility and basicity, to test for hydrogen bonding interactions, and to improve the metabolic stability, binding affinity, and bioavailability of several compounds. ${ }^{9}$ Incorporation of fluorocarbons into proteins and peptides results in the stabilization of folded proteins and promotion of self-assembly of alpha-helical peptides into coiled coils. ${ }^{10-11}$ Resistance of these structures to thermal denaturation suggests greater stability of fluorinated analogs than hydrocarbons, although it remains unclear whether this effect is due to increased hydrophobic surface area alone or to a difference in the character of hydrophobicity. 
The results of our own studies involving i) binding of ligands modified with $R_{H}$ and $R_{F}$ tails to bovine carbonic anhydrase $(\mathrm{BCA})^{12}$ and ii) denaturation of $\mathrm{BCA}$ modified with a series of $\mathrm{R}_{\mathrm{H}}$ and $\mathrm{CF}_{3}$ substituents in the presence of sodium dodecyl sulfate suggest, however, that the free energy of interaction of $\mathrm{R}_{\mathrm{H}}$ and $\mathrm{R}_{\mathrm{F}}$ with hydrophobic surfaces can be rationalized entirely or predominantly based on the amount of solvent-accessible surface area $\left(\mathrm{CF}_{3} \mathrm{CONH}\right.$ groups are $0.05-0.07 \mathrm{kcal} \mathrm{mol}^{-1}$ more hydrophobic than $\mathrm{R}_{\mathrm{H}} \mathrm{CONH}$ groups with the same surface area). (A previous paper and relevant reviews summarize the background on the hydrophobic effect due to $\left.\mathrm{R}_{\mathrm{F}}\right) .^{13-14}$

The thermodynamics of association of series of ligands presenting $R_{H}$ and $R_{F}$ groups with human carbonic anhydrase. The current study uses isothermal titration calorimetry to measure the values of the free energy $\left(\Delta G^{\circ}{ }_{\mathrm{b}}\right)$, enthalpy $\left(\Delta H^{\circ}{ }_{\mathrm{b}}\right)$, and entropy $\left(-\mathrm{T} \Delta S^{\circ}{ }_{\mathrm{b}}\right)$ for the binding to human carbonic anhydrase II (HCA II, EC 4.2.1.1) of two series of benzenesulfonamide ligands $\left(\mathrm{H}_{2} \mathrm{NSO}_{2} \mathrm{C}_{6} \mathrm{H}_{4} \mathrm{CONHCH}_{2} \mathrm{R}_{\mathrm{H} / \mathrm{F}}\right)$ : in one series, the substituents in the 4-position of benzenesulfonamide are $\mathrm{R}_{\mathrm{H}}$ groups of increasing length, and in the second series, the substituents are $\mathrm{R}_{\mathrm{F}}$ groups of increasing length. To compare the two series, we estimate the incremental values of the thermodynamic parameters of binding $\left(\Delta \Delta G^{\circ}, \Delta \Delta H^{\circ}\right.$, and $-\mathrm{T} \Delta \Delta S^{\circ}$, $)$ based on measurements of $\left.i\right)$ the molecular surface area, and ii) the molecular volume of the $R_{H}$ and $R_{F}$ groups in the crystal structures of the protein-ligand complexes. We determined that values of $\Delta \Delta G^{\circ}$ are indistinguishable within statistical uncertainty (for $\mathrm{R}_{\mathrm{H}} \Delta \Delta G_{\mathrm{b}}^{\circ}=-12 \pm 1 \mathrm{cal} \mathrm{mol}^{-1} \AA^{-2}$; for $\mathrm{R}_{\mathrm{F}} \Delta \Delta G_{\mathrm{b}}^{\circ}=-14 \pm 1 \mathrm{cal} \mathrm{mol}^{-1} \AA^{-2}$ ), on the basis of ligand solventaccessible surface area and on the basis of the volume of the ligand (for $\mathrm{R}_{\mathrm{H}} \Delta \Delta G_{\mathrm{b}}^{\circ}=-20 \pm 2 \mathrm{cal} \mathrm{mol}^{-1}$ $\AA^{-3}$; for $\mathrm{R}_{\mathrm{F}} \Delta \Delta G^{\circ}{ }_{\mathrm{b}}=-20 \pm 2 \mathrm{cal} \mathrm{mol}^{-1} \AA^{-3}$ ) (Table 1). Both alkyl and fluoroalkyl groups contribute to $\Delta \Delta G^{\circ}$ b through favorable values of both $\Delta \Delta H^{\circ}{ }_{\mathrm{b}}$ and $-\mathrm{T} \Delta \Delta S_{\mathrm{b}}^{\circ}$. The magnitude of $\Delta \Delta H^{\circ}{ }_{\mathrm{b}}$ is indistinguishable (within experimental error) for alkyl and fluoroalkyl groups (for alkyls $\Delta \Delta H^{\circ}{ }_{\mathrm{b}}=-5 \pm 1$ cal $\mathrm{mol}^{-1} \AA^{-2}$ and for fluoroalkyls $\Delta \Delta H^{\circ}{ }_{\mathrm{b}}=-7 \pm 1 \mathrm{cal} \mathrm{mol}^{-1} \AA^{-2}$ ). Alkyls and fluoroalkyls also have indistinguishable values of $-\mathrm{T} \Delta \Delta S_{\mathrm{b}}^{\circ}$ (for alkyls $-\mathrm{T} \Delta \Delta S_{\mathrm{b}}^{\circ}=-7 \pm 1 \mathrm{cal} \mathrm{mol}^{-1} \AA^{-2}$, for fluoroalkyls $-\mathrm{T} \Delta \Delta S_{\mathrm{b}}^{\circ}=-7 \pm 1 \mathrm{cal} \mathrm{mol}^{-1} \AA^{-2}$ ). Table 1 summarizes the results of this study as a guide to subsequent details. 
We used para-substituted benzenesulfonamides connected to hydrophobic side-chains_-"greasy tails" ${ }^{\prime \prime}$-via an amide linkage $\left(\mathrm{H}_{2} \mathrm{NSO}_{2} \mathrm{C}_{6} \mathrm{H}_{4}-\mathrm{CONHCH}_{2}\left(\mathrm{CX}_{2}\right)_{\mathrm{n}} \mathrm{CX}_{3}\right.$, where $\left.\mathrm{n}=0-4, \mathrm{X}=\mathrm{H}, \mathrm{F}\right)$ as ligands for HCA II.

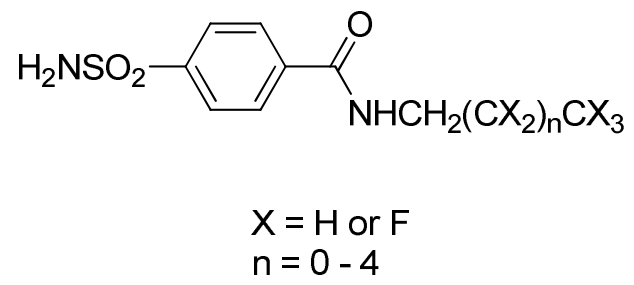

In the system of HCA II and derivatives of benzenesulfonamide, association of the benzenesulfonamide moiety ( ${ }^{-} \mathrm{HNSO}_{2} \mathrm{C}_{6} \mathrm{H}_{4}-$ ) is essentially invariant to most changes in the structure of the $\mathrm{R}$ group in $\mathrm{H}_{2} \mathrm{NSO}_{2} \mathrm{C}_{6} \mathrm{H}_{4} \mathrm{R}$ group. ${ }^{15}$ Binding is determined by association of this ${ }^{-} \mathrm{HNSO}_{2} \mathrm{C}_{6} \mathrm{H}_{4}{ }^{-}$ group to the active site $\mathrm{Zn}^{2+}$ ion, and many biostructural data establish that the geometry of the phenyl group in the active site is highly conserved. ${ }^{16}$ We have used the extreme simplicity of the system of HCA (or structurally very similar BCA) as the basis for detailed physical-organic studies of binding of ligands to HCA II. ${ }^{15}$

This paper reports the values of free energy of binding $\left(\Delta G^{\circ}\right)$, enthalpy of binding $\left(\Delta H^{\circ}\right)$, and entropy of binding $\left(-\mathrm{T} \Delta S^{\circ}{ }_{\mathrm{b}}\right)$ for the two series of ligands $\left(\mathrm{R}=\mathrm{R}_{\mathrm{H}}, \mathrm{R}_{\mathrm{F}} ; \mathrm{H}_{2} \mathrm{NSO}_{2} \mathrm{C}_{6} \mathrm{H}_{4} \mathrm{CONHR}\right)$ measured using isothermal titration calorimetry (ITC). We calculated the incremental changes in free energy, enthalpy, and entropy $\left(\Delta \Delta G^{\circ}{ }_{\mathrm{b}}, \Delta \Delta H^{\circ}{ }_{\mathrm{b}}\right.$ and $\left.-\mathrm{T} \Delta \Delta S^{\circ}{ }_{\mathrm{b}}\right)$ of binding by correlating the thermodynamic parameters for binding with i) the change in solvent-accessible surface area of binding, and ii) the molecular volume of the ligand. These incremental values represent the contribution to binding per unit area of hydrocarbon-hydrocarbon and hydrocarbon-fluorocarbon interaction, and per unit volume of hydrocarbon or fluorocarbon for each series.

Residues Phe131, Val135, Pro202, and Leu204 comprise the so-called 'hydrophobic wall' of HCA II. ${ }^{15}$ We guessed, based on the crystallography of structurally similar ligands, and validated by our own structural studies, that the hydrophobic tails of para-substituted benzenesulfonamides would form van der Waals contacts with the hydrophobic wall. Many examinations of ligands for HCA II (and BCA II) 
have demonstrated that hydrophobic groups-and specifically groups of type $\mathrm{H}_{2} \mathrm{NSO}_{2} \mathrm{C}_{6} \mathrm{H}_{4}$ $\mathrm{CONHCH}_{2} \mathrm{R}$, with $\mathrm{R}=\mathrm{n}$-alkyl, n-fluoroalkyl-increase their strength of binding as the putative area of contact between the ligand and the protein increases. The system that examines binding of benzenesulfonamide ligands $\left(\mathrm{H}_{2} \mathrm{NSO}_{2} \mathrm{C}_{6} \mathrm{H}_{4}-\mathrm{R}\right.$, where $\mathrm{R}$ represents various organic moieties $)$ to carbonic anhydrase is thus an excellent one (the best, we believe, so far developed) for physical-organic studies of the hydrophobic effect in a biologically relevant system comprising protein and ligand. ${ }^{15}$ It is particularly interpretable since the rigidity of the tertiary structure of CA II makes contributions to binding from protein plasticity negligible. ${ }^{15}$

The first objective of this study was to explore the relationship between the hydrophobic effect and ligand structure, using two chemically different, but structurally related classes of hydrophobic groups: alkyls $\left(R_{H}\right)$ and fluoroalkyls $\left(R_{F}\right)$. Our hypothesis was that either: i) The hydrophobic effect is due primarily to exclusion of water from the hydrophobic surfaces of the active site and of the ligand; in which case, the magnitude of the effect for homologous $R_{H}$ and $R_{F}$ tails interacting with the hydrophobic wall of HCA II would be the same when adjusted for differences in the solvent-accessible surface areas of the tails. ii) The hydrophobic effect results from the physical properties of $R_{H}$ and $R_{F}$ (i.e., polarizability, van der Waals interactions, etc.); in which case, the magnitude of the effect might be quite different for the two types of tails, since these properties are different for $R_{H}$ and $R_{F}$.

Our second objective in comparing $\mathrm{R}_{\mathrm{H}}$ and $\mathrm{R}_{\mathrm{F}}$ was to define their relative hydrophobicity in the context of protein-ligand interactions. Incorporation of fluorine into small molecules is an important tactic in designing inhibitors of proteins. ${ }^{17}$ This strategy is often used to increase binding affinity, to improve membrane permeability, and to augment metabolic stability of pharmaceuticals. There is a widespread belief-based primarily and qualitatively on the hydrophobicity and oleophobicity of Teflon—-that $\mathrm{R}_{\mathrm{H}}$ and $\mathrm{R}_{\mathrm{F}}$ are fundamentally different in their hydrophobicity. ${ }^{18}$ In many (in fact, most) of the systems studied, the hydrophobicities for $\mathrm{R}_{\mathrm{H}}$ and $\mathrm{R}_{\mathrm{F}}$ are different, but there is no thermodynamic evidence to support this argument. 
Improved understanding of hydrophobic interactions involving $R_{H}$ and $R_{F}$ in the context of proteinligand binding will clarify the nature of the hydrophobic effect in biomolecular recognition, assist advances in the rational design of inhibitors for enzymes, and help to understand the basis of interactions of both fluorocarbons and hydrocarbons with proteins.

Aliphatic Fluorocarbons and Hydrocarbons. Alkyl and fluoroalkyl groups have considerably different properties, including: i) refractive indexes (1.2515 for hexane and 1.3751 for perfluorohexane); ${ }^{14}$ ii) dipole moments $\left(1.85 \mathrm{D}\right.$ for $\mathrm{CH}_{3} \mathrm{~F}, 1.64 \mathrm{D}$ for $\left.\mathrm{CHF}_{3}\right)$; iii) $\mathrm{C}-\mathrm{X}$ bond lengths $(1.09 \AA$ for $\mathrm{X}=\mathrm{H}$, and $1.35 \AA$ for $\mathrm{X}=\mathrm{F}){ }^{19}$ iv) van der Waals radii $(1.20 \AA$ for $\mathrm{H}, 1.47 \AA$ for $\left.\mathrm{F}) \dot{ }^{19} \mathrm{v}\right)$ molecular surface areas ( $46 \AA^{2}$ for $-\mathrm{CH}_{3}, 59 \AA^{2}$ for $\left.-\mathrm{CF}_{3}\right)$; vi) conformations of $\mathrm{X}$ with respect to the $\mathrm{C}$ C bond (all-antiperiplanar vs. helical) ${ }^{14}$ and vii) solubility in water.

The Classical View of Hydrophobic Interactions. The term "'hydrophobic interaction', which implies the tendency of a nonpolar surface to minimize contact with water, refers to the favorable free energy of formation of aggregates of hydrated hydrocarbons (or fluorocarbons) in water. ${ }^{2,4-5}$ Early thermodynamic analyses by Frank and Evans indicated that the unfavorable free energy of dissolution of nonpolar gases in water was determined by an unfavorable entropic term at room temperature, where the enthalpy of dissolution is nearly zero. ${ }^{20}$ As temperature increased, however, the magnitude of the enthalpy of dissolution of nonpolar gases also increased. This obervation indicates that the change in heat capacity of dissolving nonpolar solutes in water is positive. Both the increase in heat capacity and the unfavorable entropy at room temperature led Frank and Evans to rationalize the poor solubility of nonpolar compounds in water to be the result of an increase in the order of the water that solvates these compounds, and they introduced the term "iceberg" to describe the structure of water molecules that hydrate nonpolar solutes. $^{20}$

Kauzmann-based on the analyses of Frank and Evans—hypothesized that the folding of proteins was due to an unfavorable entropy of hydrating the nonpolar side chains of Val, Leu, Ile, and Phe. ${ }^{1}$ Kauzmann inferred that ordering of water molecules near hydrophobic amino acids in solution might explain the entropic driving force for the folding of proteins. At the same time, structural studies of 
methane hydrates showed that the ordering of water around methane in the solid state produced a network of hydrogen bonds that is almost indistinguishable from the structure of hexagonal ice. ${ }^{21}$ Tanford coined the term "hydrophobic effect" for the unfavorable free energy of hydration of nonpolar molecules in water. ${ }^{22}$

Modern Views of Hydrophobic Interactions. The community of biophysical chemists, in the decades since, has embraced the concept that water is more ordered near hydrophobic solutes than it is in the bulk. Most of the support for structured water, however, derives from spectroscopic studies of water near macroscopic interfaces with nonpolar phases, ${ }^{23-26}$ while a few studies (by neutron diffraction spectroscopy) of solutions of nonpolar solutes in water seem to provide contradicting results. ${ }^{27-28}$ Theoretical studies in the decades since $\mathrm{KT}$, too, seem to provide conflicting results: although some theoretical treatments of hydrophobic effects—-primarily those presented by Stillinger, Pratt, Chandler, Hammer, and others_-predict structured water near extended $\left(>1 \mathrm{~nm}^{2}\right)$ surfaces, and a lack of structured water near smaller solutes, ${ }^{29-32}$ molecular dynamics simulations that have explicitly studied the behavior of water near small nonpolar solutes have, in many cases, supported the original KT speculation. ${ }^{33-35}$ Little consensus exists in the literature to support the notion of structured water near small solutesthose having areas less than $\sim 1 \mathrm{~nm}^{2}$-in aqueous solution. ${ }^{5,7}$ Moreover, little work has focused on the behavior of water near fluoroalkyl groups in aqueous medium. ${ }^{13}$

Hydrophobic Interactions in Protein-Ligand Association. Molecular dynamics simulations of water in the binding pockets of proteins portray the complicated nature of the structure and energy of water near protrusions and cavities on the surfaces of proteins. ${ }^{36-43}$ Simulations predict that i) water in a hydrophobic cavity is less favorable in enthalpy than water in bulk solution because, near hydrophobic groups in these cavities, waters form fewer hydrogen bonds than does water in bulk solution, and ii) water near polar groups, by contrast, form hydrogen bonds with the entropic cost of being more ordered than water in bulk solution. ${ }^{41}$

This complicated picture of water in protein binding pockets coincides with thermodynamic signatures of hydrophobic interactions that are somewhat different from those of the hydrophobic effects described 
by KT. Numerous experimental studies of protein-ligand association have demonstrated that negative values for the change in constant pressure heat capacity of binding $\left(\Delta \mathrm{Cp}^{\circ}{ }_{\mathrm{b}}\right)$, rather than unfavorable values of $-\mathrm{T} \Delta S^{\circ}{ }_{\mathrm{b}}$, correlate with hydrophobic interactions in protein binding. ${ }^{44-51}$ Nonetheless, the repeated observation that binding of hydrophobic molecules to proteins has negative values of $\Delta \mathrm{Cp}^{\circ}{ }_{\mathrm{b}}$ is consistent with the hypothesis that the structure of water in the binding pockets of proteins determines the thermodynamics of hydrophobic effects.

\section{Experimental Design.}

Choice of Protein-Ligand System. We choose HCA II as a model system for our physical-organic study for five reasons: i) HCA II is an exceptionally stable and rigid protein. It can be obtained readily by expression in E. Coli ( $100 \mathrm{mg} \mathrm{L}^{-1}$ of growth medium) using techniques with which we are familiar, and obtained in the quantities necessary for ITC $(\sim 0.5 \mathrm{mg} \text { per experiment })^{52}$ and X-ray crystallography; ii) numerous benzenesulfonamide-containing ligands $\left(\mathrm{H}_{2} \mathrm{NSO}_{2} \mathrm{C}_{6} \mathrm{H}_{4}-\mathrm{R}\right.$, with some constraints on $\left.\mathrm{R}\right)$, bind in the active site of HCA II with a conserved geometry; ${ }^{15}$ iii) previous X-ray and neutron crystallographic studies have detailed the structure of sulfonamide ligands bound in the active site of $\mathrm{HCA} ;{ }^{15,53}$ iv) a single protocol for growing crystals of the protein with different ligands can be used; v) one face of the active site of HCA II is a hydrophobic "shelf" or "wall", comprising residues Phe131, Val135, Pro202, and Leu204. ${ }^{15}$ This wall has $~ 250 \AA^{2}$ of solvent-accessible hydrophobic surface, and substituents in the para-position of benzenesulfonamide are positioned over that part of the active site

\section{(Figure 1).}

Perturbational Approach for Probing Binding. To probe the interactions of "'greasy tails" with the hydrophobic region adjacent to the active site of HCA II, we have followed a perturbational approach: we used the para-carboxamido benzenesulfonamide group to anchor the ligand in the active site of the protein in a well-defined, conserved geometry, and we systematically varied the length of $R_{H}$ and $R_{F}$ chains $\left(\left(\mathrm{CX}_{2}\right)_{\mathrm{n}}\right.$, where $\mathrm{X}=\mathrm{H}, \mathrm{F}$ and $\left.\mathrm{n}=0-4\right)$ in the para-position. Previous structural analyses-and data we present here-indicated that this anchor would preserve the geometry of the arylsulfonamide 
group, which makes the dominant contribution to thermodynamics of binding in this system $(\sim 8 \mathrm{kcal}$ $\mathrm{mol}^{-1}$ ), regardless of the nature of the greasy tail. ${ }^{16}$ This structural rigidity is essential to the perturbational approach that we use because, as we show below, the difference in the contribution to the thermodynamics of the interaction between methylene or fluoromethylene groups and the hydrophobic wall of HCA is less than $0.5 \mathrm{kcal} \mathrm{mol}^{-1}$.

Since this value is roughly the same as the uncertainty in the measurement of $\Delta H^{\circ}$ (or $-\mathrm{T} \Delta S^{\circ}{ }_{\mathrm{b}}$ ) by ITC for any single ligand, the comparison of any pair of ligands would not be statistically meaningful. The perturbational approach, which in this work includes analyses of five ligands of each series, thus allows us to evaluate the similarities (or differences) between $\mathrm{R}_{\mathrm{H}}$ and $\mathrm{R}_{\mathrm{F}}$ tails with greater precision than would be possible for pairs of structurally homologous compounds.

One potential limitation of using the $p$-carboxamido benzenesulfonamide anchor-rather than the $N$ methylcarboxamides, for example_could be differences in the values of $\mathrm{pK}_{\mathrm{a}}$ of the carboxamide group for $\mathrm{R}_{\mathrm{H}}$ and $\mathrm{R}_{\mathrm{F}}$ series. Involvement of the amide $\mathrm{NH}$ group may contribute favorably to the enthalpy of binding via hydrogen-bonding $\left(\mathrm{NH} \cdots \mathrm{H}_{2} \mathrm{O} \cdots \mathrm{Th}\right.$ 200, Pro201), a hydrogen bond that we observe by X-ray crystallography (Figure S4 in Supporting Information). In our previous studies, indeed, we demonstrated that the $\mathrm{pK}_{\mathrm{a}}$ of the carboxamide group for the $\mathrm{R}_{\mathrm{F}}$ series is lower than that of the $\mathrm{R}_{\mathrm{H}}$ series, and the value of $\Delta G^{\circ}$ of the $\mathrm{R}_{\mathrm{F}}$ tails were more favorable than that of the $\mathrm{R}_{\mathrm{H}}$ tails. ${ }^{12}$ In that work, however, we also measured the values of $\Delta \Delta G^{\circ}$ for both series of $N$-methylcarboxamides and determined that the difference in the $\mathrm{pK}_{\mathrm{a}}$ of the carboxamide group did not influence the values of $\Delta \Delta G^{\circ}$ for either the $\mathrm{R}_{\mathrm{H}}$ or the $\mathrm{R}_{\mathrm{F}}$ series. We also show here that, although the NMR shifts of the carboxamide protons of $\mathrm{R}_{\mathrm{H}}$ and $\mathrm{R}_{\mathrm{F}}$ are different, they are the same across each series, and we infer that the values of $\Delta \Delta H^{\circ}{ }_{\mathrm{b}}$ and $-\mathrm{T} \Delta \Delta S_{\mathrm{b}}^{\circ}$ reflect contributions from the hydrophobic interactions between $\mathrm{R}_{\mathrm{H} / \mathrm{F}}$ and the hydrophobic wall.

From our previous work with these groups, we anticipated negative values of $\Delta \Delta G^{\circ}{ }_{\mathrm{b}}$ for both $\mathrm{R}_{\mathrm{H}}$ and $\mathrm{R}_{\mathrm{F}}$ tails. ${ }^{12}$ Our objective was to analyze the enthalpic and entropic contributions to this free energy of 
binding by using ITC, and to correlate these contributions with the structures and physical properties of the molecules.

\section{Results}

Synthesis of the Ligands. We prepared benzenesulfonamides with alkyl and fluoroalkyl tails following the previously reported procedures. ${ }^{12}$

Purification of the Protein. To purify HCA II (E.C. 4.2.1.1, > 95\% pure), we followed the procedures reported by Fierke et al., who also kindly provided the plasmids containing the gene for the protein. ${ }^{54-56}$ Details of this procedure appear in the Supporting Information (available online at pubs.acs.org).

Collection of Data by ITC. Because of the low solubility $(<50 \mu \mathrm{M})$ in aqueous buffer of the ligands that had long $(\mathrm{n}>2)$ tails, we expected it to be challenging to conduct ITC experiments, which require that the concentration of molecule in the cell of the calorimeter to be no higher than $10^{3} \times K_{\mathrm{d}}$, and that the concentration of molecule in the syringe be $\sim 10$ times the concentration of the molecule in the cell. ${ }^{52}$ Placing solutions of ligand in the cell not only set a lower limit on the concentration of ligand needed, but also allowed us to minimize the contribution to the uncertainty in $\Delta \Delta H^{\circ}$ brom the uncertainty in the concentration of ligand. ${ }^{57} \mathrm{We}$ titrated aliquots of HCA II $(20 \mu \mathrm{M})$, taken from a single batch, into solutions of each of the 10 ligands $(\sim 2.0 \mu \mathrm{M})$. By assuming that the concentration of active protein was the same in each experiment, we were able to adjust the stoichiometry of protein-ligand binding to $\mathrm{n}=1$ during analysis of the data. ITC experiments with each ligand were repeated 7-9 times. We report the average values of $\Delta G^{\circ}, \Delta H^{\circ}{ }_{\mathrm{b}}$ and $-\mathrm{T} \Delta S^{\circ}{ }_{\mathrm{b}}$ and estimate their uncertainties as standard deviations (for number of repeated experiments $\mathrm{N} \geq 7$ ).

$\Delta \mathbf{G}^{\circ}{ }_{b}$ is proportional to the solvent-accessible surface area of the ligand. ITC experiments confirmed our previous observation that extending the length of the "greasy tail" resulted in more negative values of $\Delta G^{\circ}$ and lower values of $K_{\mathrm{d}}$ for dissociation from HCA II (Figure 2). Fluoroalkyls, in general, display higher affinity $\left(\sim 1 \mathrm{kcal} \mathrm{mol}^{-1}\right)$ for HCA II than alkyls with the same number of 
carbon atoms in the "greasy tail". We rationalize this effect, at least in part, by the fact that $\mathrm{CF}_{2}$ groups have larger hydrophobic surface area than $\mathrm{CH}_{2}$ groups (see below). The electron-withdrawing properties of fluoroalkyl chains, and their absence in alkyl chains, moreover, result in more acidic amidic $\mathrm{NH}$ in fluoroalkyl amides $\left(\mathrm{Ar}-\mathrm{CONHCH}_{2} \mathrm{R}_{\mathrm{F}}\right)$ than in alkyl amides $\left(\mathrm{Ar}-\mathrm{CONHCH}_{2} \mathrm{R}_{\mathrm{H}}\right)$. This inference of a difference in acidity is supported by chemical shifts in ${ }^{1} \mathrm{H}$ NMR spectra (Figure S5 in Supporting Information). Table 2 summarizes the thermodynamic values for binding of para-substituted benzenesulfonamides to HCA II.

Based on our X-ray crystallographic analysis of HCA II-ligand complexes (see later in this paper), we excluded the datapoint for the longest fluoroalkyl ligand $(X=F, n=4)$ from the analysis of thermodynamics of interactions for $\mathrm{R}_{\mathrm{F}}$ (for free energy, enthalpy and entropy of binding; see below). The crystal structure of HCA II in the complex with the fluoroalkyl ligand that contains the longest sidechain $(\mathrm{n}=4)$, in contrast to structures with all other fluoroalkyl and alkyl ligands, shows that Gln136 flips its orientation (the gauche conformation in the case of $\mathrm{X}=\mathrm{F}, \mathrm{n}=4$, and the anti conformation in all other cases).

Both series of ligands display a favorable incremental entropy of binding. Figure 3 shows that the free energies of binding for both series of ligands $\left(R_{H}\right.$ and $\left.R_{F}\right)$ have a favorable entropic contribution that increases with the length of the hydrophobic tail (for alkyls $-\mathrm{T} \Delta \Delta S_{\mathrm{b}}^{\circ}=-7 \pm 1 \mathrm{cal} \mathrm{mol}^{-1} \AA^{-2}$, for fluoroalkyls $-\mathrm{T} \Delta \Delta S_{\mathrm{b}}^{\circ}=-7 \pm 1 \mathrm{cal} \mathrm{mol}^{-1} \AA^{-2}$ ). This contribution could be i) related to changes in the structure of the network of waters that hydrate the ligand and/or the active site of the protein, ii) the result of a change in the conformational degrees of freedom of the tail on binding, or (in principle) iii) the result of changes in the conformational degrees of freedom of amino acid side chains on binding of ligand.

Both series of ligands also display a favorable incremental enthalpy of binding. Extending the chain length of alkyl and fluoroalkyl tails also contributed to the free energy of binding through a favorable enthalpic term (Figure 4). The slope of enthalpy as a function of chain length (or ligand solvent-accessible surface area) is indistinguishable for alkyl and fluoroalkyl tails (from the alkyl data, 
$\Delta \Delta H_{\mathrm{b}}^{\circ}=-5 \pm 1 \mathrm{cal} \mathrm{mol}^{-1} \AA^{-2}$, and from the fluoroalkyl data, $\Delta \Delta H_{\mathrm{b}}^{\circ}=-7 \pm 1 \mathrm{cal} \mathrm{mol}^{-1} \AA^{-2}$; the uncertainties in these values overlap).

Crystallization of Protein-Ligand Complexes. We grew crystals of HCA II in conditions reported by McKenna and coworkers (1.15 M sodium citrate, $100 \mathrm{mM}$ Tris hydrochloride, $\mathrm{pH}=7.8)$ because under these conditions, crystals of the native protein diffract X-rays to $\sim 1.0 \AA$ resolution. ${ }^{29}$ We performed soaking experiments using the ligands with short $(\mathrm{n}=0$ or 1$)$ tails by transferring crystals from their mother liquor to a fresh drop that contained sodium citrate (1.32 M), Tris (100 mM), and ligand $(20-450 \mu \mathrm{M})$. The ligands with $\mathrm{n} \geq 2$ were insoluble in sodium citrate, which prohibited its use as the medium for soaking experiments.

We expected that the solubility of the ligands would be higher in solutions containing polyethylene glycol (PEG, $30-35 \%$ ) than in sodium citrate, but were unable to grow crystals of HCA II in solutions of PEG. We chose, thus, a solution condition (PEG 1500, $20 \%$; HEPES $100 \mathrm{mM}$ ) that was slightly higher in concentration of PEG than conditions reported previously to crystallize HCA II in the same polymorph as our crystals, and we transferred crystals of native HCA II, grown in sodium citrate, into drops containing PEG and saturated with ligands with longer $(n \geq 2)$ tails. The strategy was successful in that the resulting crystals diffracted X-rays to $1.5-1.8 \AA$ resolution, and the maps of electron density derived from molecular replacement indicated the presence of ligand (Figure S4 in Supporting Information). We refined the crystal structures of each of the ten HCA II-ligand complexes at high resolution $(1.83-1.05 \AA$ ) data (Table 2, Table S1 in Supporting Information).

Structural Characterization of the Protein-Ligand Complexes. To determine whether the thermodynamic trends in binding were the result of structural changes to the protein, we aligned the ten structures and calculated the root-mean-squared deviation (RMSD) for all atoms of the proteins. The average value for RMSD for these structures was $0.091 \AA$, a result that indicated that the conformation of the protein did not depend on the identity of ligand bound in the active site.

To verify our assumption that the geometry of the ligands in the active site of HCA II was conserved for each complex, we aligned the atoms of the ten HCA II-ligand complexes, and calculated the RMSDs 
for the atoms of the ligands and the $\mathrm{Zn}^{2+}$ ion (Figure 5). The 10 ligands had the same geometries of binding: the average value of RMSD for the alignment of the heavy atoms of the ligand, the $\mathrm{Zn}^{2+}$ ion, and the heavy atoms of residues His94, His96, His119, Phe131, Thr200 (chosen arbitrarily to allow the three-dimensional alignment) was $0.064 \AA$, the data that justified our assumption that the carboxybenzenesulfonamide group, the $\mathrm{Zn}-\mathrm{N}$ bond, and the interaction between the carboxamide group and the protein-bound water at Thr200 were indistinguishable for the ten complexes.

The structure of HCA II is invariant in nine of ten crystal structures of ligand complexes that we solved, the exception being the structure of HCA II in complex with the longest fluoroalkyl tail (X = F, $\mathrm{n}=4$, Figure 6). In this case, the side chain of Gln136, which is at the edge of the hydrophobic shelf, flips to contact the terminal $-\mathrm{CF}_{3}$ group of the tail. That flip of conformation induces a gauche conformation of the Gln136 side chain (Figure 6B). The number of crystallographically defined water molecules within $4 \AA$ of the $-\mathrm{CONH}_{2}$ group of Gln136, however, did not change: each of the two possible conformations of Gln136 showed four contacts with ordered molecules of water in the crystal structures (Figure S7 in Supporting Information). Crystallography of the protein-ligand complexes verified that the ligands bind to the active site in the same geometry, and that extension of the tails increased the putative surface of contact between the ligand and the protein.

For the $\mathrm{R}_{\mathrm{H}}$ series, all of the contacts between the tail and the hydrophobic wall occurred between methylene and methyl groups of the tails and methyl groups of Val135 and Leu204, methylene groups of Pro202, and methine groups of Phe131. This observation validated our first-order analysis of hydrophobic effects in the linear trends in $\Delta H^{\circ}{ }_{\mathrm{b}}$ and $-\mathrm{T} \Delta S^{\circ}{ }_{\mathrm{b}}$ across the series. For the $\mathrm{R}_{\mathrm{F}}$ series, similarly, crystallography validated our first-order analysis of linear trends in $\Delta H^{\circ}{ }_{\mathrm{b}}$ and $-\mathrm{T} \Delta S^{\circ}{ }_{\mathrm{b}}$ for the ligands $n=0-3$, and indicated potential causes (i.e., polar contacts, steric interactions, changes in the hydration of protein, and change in the conformation of Gln136) for deviations from those trends for the ligand $n=4$.

Crystallography provides no direct evidence concerning the hydration of the hydrophobic wall or the structure of the network of hydrogen bonds among molecules of water at the surface. It is interesting, 
however, to analyze both the regions of the active site in which crystallographic waters appear, and those in which they do not. We analyzed three recent structures of HCA II that were solved by high resolution $(\sim 1.0 \AA)$ X-ray diffraction and by neutron diffraction. ${ }^{30}$ These structures show that more than $90 \%$ of the observable (crystallographic) waters are in indistinguishable positions. Interestingly, however, no crystallographically identifiable molecules of water appear within $3 \AA$ of the hydrophobic wall. This observation provides no positive support for the idea of structured water near a hydrophobic surface in HCA II (although it also does not demonstrate the absence of such structure).

\section{Discussion}

Negative values of $\Delta \Delta G^{\circ}{ }_{\mathrm{b}}\left(\Delta G^{\circ}{ }_{\mathrm{b}, \mathrm{n}+1}-\Delta G^{\circ}{ }_{\mathrm{b}, \mathrm{n}}=\Delta G^{\circ}{ }_{\mathrm{CX} 2}\right.$, protein $-\Delta G^{\circ}{ }_{\mathrm{CX} 2}$, solv $)$ could be the result of $\left.\mathrm{i}\right)$ favorable desolvation of the protein and/or the ligand (i.e., $-\Delta \Delta G^{\circ}{ }_{\mathrm{CX} 2}$, solv $<0$ ), ii) favorable interactions (dispersion interactions) between the alkyl and fluoroalkyl tails of the ligand and the hydrophobic wall (i.e., $\Delta \Delta G^{\circ} \mathrm{CX} 2$, protein $<0$ ), iii) an increase in conformational degrees of freedom of the ligand or protein on binding (i.e., $\Delta \Delta G^{\circ} \mathrm{CX} 2$, protein $<0$ ), or iv) favorable solvation of the protein-ligand complex (i.e., $\Delta \Delta G^{\circ}{ }_{\mathrm{CX} 2}$, protein $\left.<0\right)$. The analysis we describe below indicates that desolvation of the greasy tails and of the hydrophobic wall determine the thermodynamics of binding in this system.

Dehydration of the ligand accounts for the favorable entropy of binding. Our ITC data show that the entropy of binding becomes more favorable with larger alkyl and fluoroalkyl tails (for alkyls $-\mathrm{T} \Delta \Delta S_{\mathrm{b}}^{\circ}=-7 \pm 1 \mathrm{cal} \mathrm{mol}^{-1} \AA^{-2}$, for fluoroalkyls $-\mathrm{T} \Delta \Delta S_{\mathrm{b}}^{\circ}=-7 \pm 1 \mathrm{cal} \mathrm{mol}^{-1} \AA^{-2}$, Table 1). There are at least four ways to explain a favorable incremental entropy of binding for $\mathrm{R}_{\mathrm{H}}$ and $\mathrm{R}_{\mathrm{F}}$ :

First, as Kauzmann and Tanford would have predicted, the desolvation of $\mathrm{R}_{\mathrm{H}}$ and $\mathrm{R}_{\mathrm{F}}$ could be entropically favorable (i.e., $\mathrm{T} \Delta \Delta S^{\circ} \mathrm{CX} 2$, solv $>0$ ). We assume-based on the large number of calorimetric data for the transfer from octanol into aqueous phase, and for transfer from aqueous phase to vacuum of homologous alkyl-alcohols, and alkyl-amides ${ }^{31-32}$ - that the incremental entropy of desolvation of the $\mathrm{R}_{\mathrm{H}}$ tails is favorable $\left(-\mathrm{T} \Delta \Delta S^{\circ}{ }_{\mathrm{CH} 2}\right.$, solv $\left.=-0.9 \mathrm{kcal} \mathrm{mol}^{-1} \mathrm{CH}_{2}^{-1}\right){ }^{58}$ This value-which is $\sim 0.6 \mathrm{kcal}^{\mathrm{mol}}{ }^{-1}$ more favorable than $-\mathrm{T} \Delta \Delta S^{\circ}{ }_{\mathrm{b}}$ for $\mathrm{R}_{\mathrm{H}}$ and HCA II-indicates that dehydration of the tail makes the 
dominant favorable contribution to $-\mathrm{T} \Delta \Delta S^{\circ}$. It is also plausible that the conformational flexibility of the tail in the unbound state is greater than that of the tail in the bound state: loss in conformational flexibility of the tail on binding to HCA would rationalize this difference between $-\mathrm{T} \Delta \Delta S^{\circ}{ }_{\mathrm{CH} 2 \text {, solv }}$ and $-\mathrm{T} \Delta \Delta S_{\mathrm{b}}^{\circ}$. We are not aware of a calorimetric study of the solvation of aliphatic fluorocarbon compounds, presumably because their low solubility in water makes their solvation inherently difficult to study by calorimetry.

Second, Homans et al. showed in studies with major urinary protein (MUP) that increasing the number of methylene groups in ligands made unfavorable contributions to $-\mathrm{T} \Delta \Delta S_{\mathrm{b}}^{\circ}:{ }^{51}$ for the series of n-alkyl alcohols, they report a value for $-\mathrm{T} \Delta \Delta S^{\circ}{ }_{\mathrm{b}}=+412 \mathrm{cal} \mathrm{mol}^{-1} \mathrm{CH}_{2}{ }^{-1}$. Values of $-\mathrm{T} \Delta S^{\circ}$, however, include the difference in conformational mobility of the ligand between the unbound and bound states. Although the conformational mobility of alkyl chains on n-alkyl alcohols in the unbound state are likely to be similar to that of our alkyl tails in the unbound state, the conformational mobility of these groups in the bound state are determined by the structure of the binding site of the protein. The structures of the binding sites of HCA II and MUP are very different: the binding site of MUP is a narrow groove lined with Leu, Tyr, and Phe residues that completely surround its ligands, while that of HCA II is an open, conical cleft in which bound ligands retain $30-50 \%$ of their solvent-accessible surface area. It is difficult to estimate the conformational mobility of ligands in the bound state. It is plausible, however, that alkyl tails in the active site of HCA II retain more conformational mobility than do alkyl alcohols bound in the active site of MUP. ${ }^{59}$ Such a difference in conformational mobility would rationalize, at least in part, the difference in values of $-\mathrm{T} \Delta \Delta S^{\circ}$ between alkyl tails binding to HCA II and to MUP.

The third contribution to the overall $-\mathrm{T} \Delta \Delta S^{\circ}{ }_{\mathrm{b}}$ could derive from changes from conformational degrees of freedom for amino acids in the active site upon binding. Our crystallographic data indicate that this contribution is unlikely to be important, because all ligands except the longest fluorinated one $(\mathrm{X}=\mathrm{F}, \mathrm{n}$ $=4$ ) do not change the conformation of side-chains of amino acids in the proximity of ligands (the conformation of all amino acids of HCA II remain the same in complexes with $\mathrm{R}_{\mathrm{H}}$ and $\mathrm{R}_{\mathrm{F}}$ ligands, the only exception being Gln136 in the case of $\left.R_{F}, n=4\right)$. 
Fourth, there is no indication from high-resolution X-ray and neutron diffraction studies of native HCA II that molecules of water are localized near the hydrophobic wall, although configurational restriction of molecules of water that are not observable by crystallography could, at least in principle, make favorable contributions $\mathrm{T} \Delta \Delta S^{\circ}{ }_{\mathrm{CX} 2}$, protein .

Our results—an increasing favorable entropy with increasing area of alkyl and fluoroalkyl tails—are compatible with Kauzmann-Tanford's hypothesis for the origin of the hydrophobic effect: the burial of hydrophobic surface area, in both cases, is entropically favorable. The entropic contribution to $\Delta \Delta G^{\circ}{ }_{\mathrm{b}}$ appears to be dominated by the entropically favorable dehydration of the greasy tail. Although it is plausible that association with HCA II restricts the conformational flexibility of the alkyl tails, this restriction could be less unfavorable for the association of greasy tails with HCA II than it is for that of n-alkyl alcohols with MUP because of the differences in the structures of the active sites of the two proteins.

Is the favorable enthalpy of binding a result of dispersion interactions or dehydration of the hydrophobic wall of HCA II? Our ITC results show that the enthalpy of binding to HCA II becomes more favorable with larger alkyl and fluoroalkyl tails (for alkyls $\Delta \Delta H^{\circ}{ }_{\mathrm{b}}=-5 \pm 1 \mathrm{cal} \mathrm{mol}^{-1} \AA^{-2}$, for fluoroalkyls $\Delta \Delta H^{\circ}{ }_{\mathrm{b}}=-7 \pm 1 \mathrm{cal} \mathrm{mol}^{-1} \AA^{-2}$, Table 1). The values we measure for $\Delta \Delta H^{\circ}{ }_{\mathrm{b}}$ for the alkyl tails are quite different from those reported by Homans for the aliphatic alcohols binding to MUP $\left(\Delta \Delta H^{\circ}{ }_{\mathrm{b}}=-150 \pm 30 \mathrm{cal} \mathrm{mol}^{-1}\right.$ for HCA II with alkyl tails; $\Delta \Delta H^{\circ}{ }_{\mathrm{b}}=\sim-1350 \mathrm{cal} \mathrm{mol}^{-1}$ for MUP with aliphatic alcohols). Homans et al. did not compare thermodynamics of binding for aliphatic alcohols and fluorinated aliphatic alcohols, and they did not correlate the thermodynamic parameters of binding with solvent-accessible surface area of ligands.

Binding of primary alcohols $\left(\mathrm{CH}_{3}\left(\mathrm{CH}_{2}\right)_{\mathrm{n}} \mathrm{OH}, \mathrm{n}=4-9\right)$ to MUP appears to conflict with KauzmannTanford's view on the hydrophobic effect: Homans et al. found that enthalpy of binding becomes more favorable and the entropy of binding becomes less favorable with the increasing chain length of the ligands. They rationalized that trend by invoking dispersion interactions-which contribute favorably to $\Delta \Delta H^{\circ}{ }_{\mathrm{b}}$ - between the alkyl groups of the alcohols and the active site of the MUP. ${ }^{51}$ 
Previous studies of the dehydration of aliphatic compounds (and of other model compounds) suggest that the dehydration of aliphatic surface area is enthalpically unfavorable $\left(-\Delta \Delta H^{\circ}{ }_{\mathrm{CX} 2}\right.$, solv $=\sim 0.7 \mathrm{kcal}$ $\left.\mathrm{mol}^{-1}\right){ }^{51,58}$ An unfavorable value for $-\Delta \Delta H^{\circ}{ }_{\mathrm{CX} 2}$, solv paired with an overall favorable value for $\Delta \Delta H^{\circ}{ }_{\mathrm{b}}$ requires the sum of the remaining contribution to be favorable (for $\mathrm{R}_{\mathrm{H}} \Delta \Delta H^{\circ}{ }_{\mathrm{CX} 2}$, protein $=-0.9 \mathrm{kcal}$ $\mathrm{mol}^{-1}$ ). This requirement, in turn, indicates at least three possibilities to obtain the overall favorable value of $\Delta \Delta H^{\circ}{ }_{\mathrm{b}}$ that we observe experimentally: i) noncovalent interactions between the tail moieties and the hydrophobic wall make $\Delta \Delta H^{\circ}{ }_{\mathrm{CX} 2}$, protein $<0$, ii) dehydration of the hydrophobic wall of HCA II is enthalpically favorable $\left(\Delta \Delta H^{\circ}{ }_{\mathrm{CX} 2}\right.$, protein $\left.<0\right)$, or iii) hydration of protein-ligand complex is enthalpically favorable $\left(\Delta \Delta H^{\circ} \mathrm{CX} 2\right.$, protein $\left.<0\right)$.

We propose, from the comparison of thermodynamics of binding for $R_{H}$ and $R_{F}$ and from crystallography, that partial dehydration of the hydrophobic wall of HCA II upon ligand binding releases loosely bound molecules of water that are involved in hydrogen bonding interactions that are weaker than those in bulk water. This release results in the formation of stronger hydrogen-bonds among waters in the bulk - an enthalpically favorable process.

\section{Dispersion interactions presumably do not account for the enthalpic contributions to binding}

for alkyl and fluoroalkyl tails. Dispersion interactions are considerably weaker in fluorocarbon liquids than they are in hydrocarbon liquids; these interactions are determined by a low polarizability of fluorocarbons inferred from correlating the index of refraction with electronic polarizability. The difference in polarizabilities would predict that the dispersion interactions between the alkyl tails $\left(\mathrm{R}_{\mathrm{H}}\right)$ and the hydrophobic wall would be more enthalpically favorable than the analogous interactions of fluoroalkyl tails $\left(\mathrm{R}_{\mathrm{F}}\right)$ - a difference that is not observed in our measurements (for alkyls $\Delta \Delta H^{\circ}{ }_{\mathrm{b}}=-5 \pm 1$ cal $\mathrm{mol}^{-1} \AA^{-2}$, for fluoroalkyls $\Delta \Delta H^{\circ}{ }_{\mathrm{b}}=-7 \pm 1 \mathrm{cal} \mathrm{mol}^{-1} \AA^{-2}$ ). We conclude, therefore, that the difference in dispersion interactions between fluorocarbons and hydrocarbons does not account for the value of $\Delta \Delta H^{\circ}{ }_{\mathrm{b}}$ for the two series of ligands.

\section{Favorable enthalpic contribution results from non-optimal hydration of the hydrophobic wall of}

HCA II. It is plausible that the hydrophobic wall of HCA II is solvated with molecules of water that, 
because of the structure of the active site, are connected by weaker hydrogen bonds than are water molecules of the bulk. The displacement of such near-surface molecules of water (or, alternatively, of molecules of water disordered in the conical active site) by the ligand would be enthalpically favorable regardless of the structure and chemical composition of the ligand that is doing the displacement. In addition, larger ligands should displace more of these water molecules from the hydrophobic wall, and the favorable enthalpic contribution to binding would be proportional to the surface (and also volume) of the ligand.

The absence of observable, crystallographically-bound water molecules could indicate, but does not prove, that hydration of the hydrophobic wall does not occur with the ordering of water molecules that Kauzmann and Tanford suggested as being the origin of an entropy-dominated hydrophobic effect.

Crystal structures support thermodynamic data in suggesting that the molecular driving forces for binding of $R_{H}$ and $R_{F}$ to HCA II are indistinguishable. The change in conformation for Gln136 on binding correlates with a deviation in the trends of enthalpy and entropy of binding for the ligand with the longest fluoroalkyl tail compared to the other members of the series. This result suggests that the binding of alkyl and fluoroalkyl tails (except for $\mathrm{X}=\mathrm{F}, \mathrm{n}=4$ ) to HCA II is determined by similar molecular interactions (on an area- and volume-corrected basis) at the hydrophobic wall of HCA II.

The differences in polarizability of $R_{F}$ and $R_{H}$ could plausibly make the enthalpy of binding of $R_{H}$ slightly more favorable than $R_{F}$. In contrast to other alkyls $(n=0-4)$ and fluoroalkyls $(n=0-3)$, crystallographic analysis of the longest fluorinated sulfonamide $(n=4)$ shows a major structural difference compared to other tails. Gln136 possesses the gauche conformation in the case of this fluoroalkyl $(n=4)$, while in the presence of all other ligands, the anti conformation of Gln136 is observed (Figure 6). Overall, we believe that this difference contributes to the lower value of $\Delta H^{\circ}{ }_{\mathrm{b}}$ for the longest fluorinated ligand $(n=4)$, and explains the inconsistency $\left(\sim 0.4 \mathrm{kcal} \mathrm{mol}^{-1}\right.$ less than what would be predicted using the least squares linear regression fit obtained from $n=0-3$ ) in its value of $\Delta H^{\circ}$ bith those of the other fluoroalkyl ligands (Figure 4). 


\section{Conclusions}

$\mathbf{R}_{\mathbf{F}}$ and $\mathbf{R}_{\mathbf{H}}$ have indistinguishable hydrophobicities. ITC demonstrates that the increasingly favorable binding of hydrophobic tails $\left(\mathrm{R}_{\mathrm{H}}\right.$ and $\left.\mathrm{R}_{\mathrm{F}}\right)$ to HCA II with increasing length of $\mathrm{R}_{\mathrm{H}}$ or $\mathrm{R}_{\mathrm{F}}$ chain results from favorable contributions from both enthalpy and entropy. These thermodynamics also show that alkyl and fluoroalkyl tails have indistinguishable thermodynamic signatures after correction for the differences in solvent-accessible surface area. This similarity indicates that the molecular basis for increasing affinity with increasing surface area of the tail group is similar for both. Our data are consistent with the hypothesis that the hydrophobic effect, in this case, results from the exclusion of water molecules from the contact region between the hydrophobic surface of the ligand, the hydrophobic wall of HCA II, and from the active site cavity, and not from different physical properties of $\mathrm{R}_{\mathrm{H}}$ and $\mathrm{R}_{\mathrm{F}}$. Based on the thermodynamics of binding, we conclude that hydrocarbons and fluorocarbons are virtually indistinguishable when interacting with the hydrophobic surface of HCA II. Apparent differences between fluorocarbons and hydrocarbons in this study result primarily from differences in their hydrophobic surface area, and not from differences in dispersion interactions.

\section{The origin of the hydrophobic effect is release of water molecules from the protein binding} pocket and from the surface of the ligand. Most of the favorable free energy of binding is gained from interactions of water with non-polar surfaces. In this particular case, dehydration of the ligand (which presents a convex hydrophobic surface area) results in a favorable change in entropy of binding, and dehydration of the hydrophobic wall of HCA II (which is a concave hydrophobic surface area) results in a favorable change in enthalpy of binding. Theoretical studies by Rossky, Berne, Abel, Friesner and others have, time and again, suggested that the free energy of water molecules that solvate hydrophobic surfaces depend on the shape of the surface. ${ }^{36-43}$ Our experimental observations are compatible with this view, and indicate that favorable contributions to $\Delta G^{\circ}$ may arise simultaneously from the entropy of dehydration of convex surfaces (i.e., the greasy tail of the ligand) and from the enthalpy of dehydration of concave surfaces (i.e., the hydrophobic wall of the protein). 
Rational ligand design may require the explicit consideration of water. A better understanding of the thermodynamics of water interacting with non-polar surfaces in various biological systems is required for generating predictive algorithms in rational ligand design. Knowledge of the hydration of the active sites of medicinally-relevant proteins might be useful in designing high affinity ligands. Releasing water molecules of an active site that is partially (non-optimally) hydrated by a ligand would provide an enthalpically favorable component to the free energy of binding. In this respect, ligands with larger solvent-accessible surface area (and also larger volume) would release more water molecules upon binding than ligands with smaller SASA (or smaller volume). Thus, designing new inhibitors would involve an approach where ligands with larger SASA (and perhaps also volume) would be better targets than those with smaller SASA and volume. Incorporation of fluorine instead of hydrogen is one way to achieve larger SASA, but there are other functional groups (e.g., $\mathrm{CH}_{3}$ instead of $\mathrm{H}$ ) that could provide a similar effect.

Our results demonstrate that water must be considered when designing ligands to bind tightly to proteins. Structural characterization of proteins by crystallography describes only part of the influence of water on molecular recognition. Nuclear magnetic resonance may fill in some of the details, ${ }^{18}$ but its application to proteins much larger than about $25 \mathrm{kDa}$ has not yet provided detailed information about locations of water molecules. Rational ligand designers need theoretical approaches that predict accurately the structure of water in and around the active sites of proteins. Toward that aim, we believe, it is important to provide the theoretical community with the integrated structural and thermodynamic characterization of well-defined model systems of ligands and proteins against which to validate theoretical models. Carbonic anhydrase and arylsulfonamides are particularly well suited for this purpose. 
ACKNOWLEDGMENT This work was supported by the National Institute of Health (GM051559, GM030367) and a predoctoral fellowship from Eli Lilly (K.A.M.). Crystallography data for this study were measured at beamlines X25 and X29 of the National Synchrotron Light Source. Financial support comes principally from the Offices of Biological and Environmental Research and of Basic Energy Sciences of the US Department of Energy, and from the National Center for Research Resources of the National Institutes of Health grant number P41RR012408.

SUPPORTING INFORMATION. Additional thermodynamic analysis and crystallographic data. This material is available free of charge at http://pubs.acs.org. 

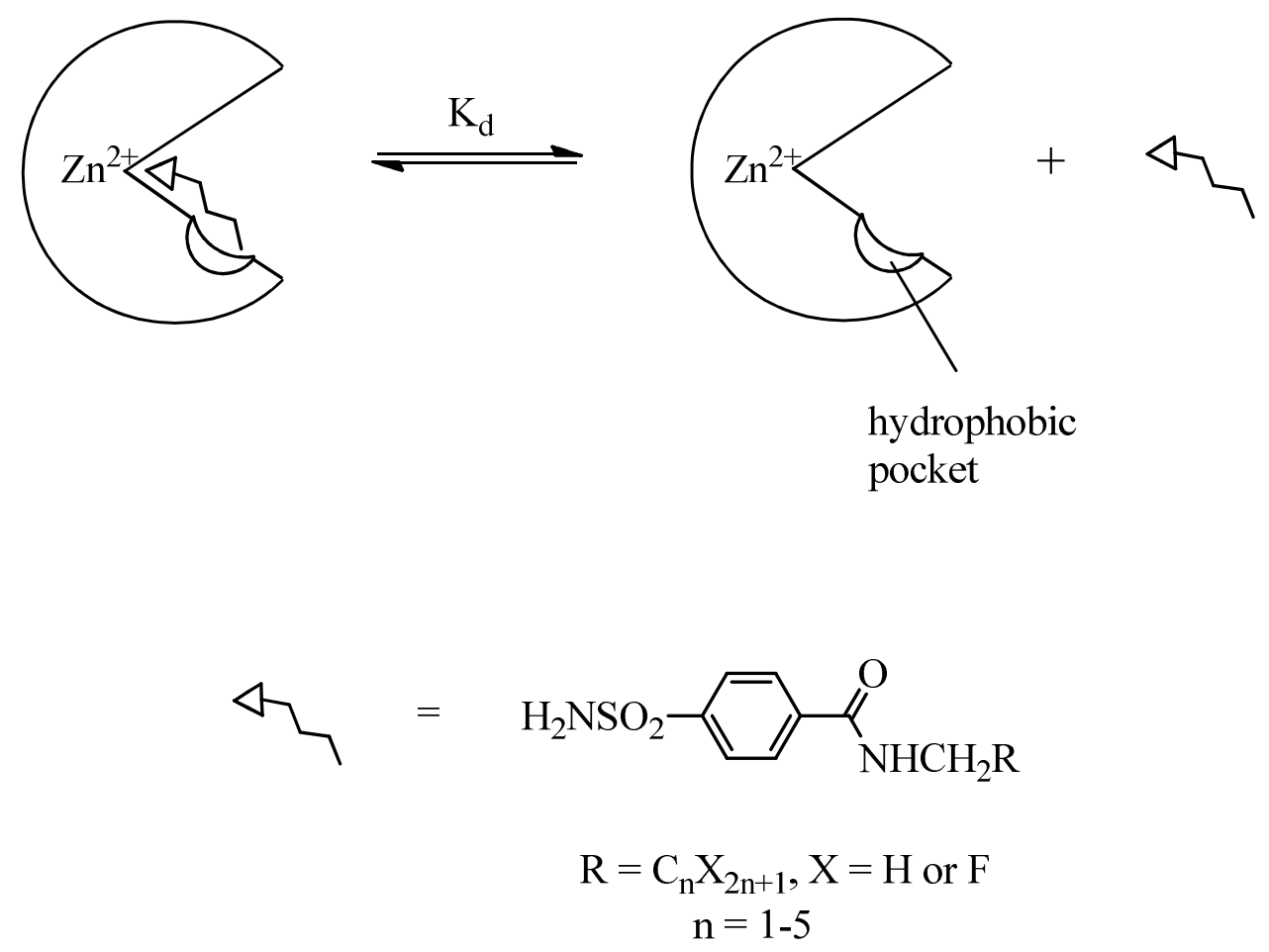

Figure 1. Our approach to increasing the binding affinity of para-substituted benzensulfonamide ligands to HCA II employs hydrophobic interactions between hydrophobic tails of ligands and the hydrophobic wall of the protein. 


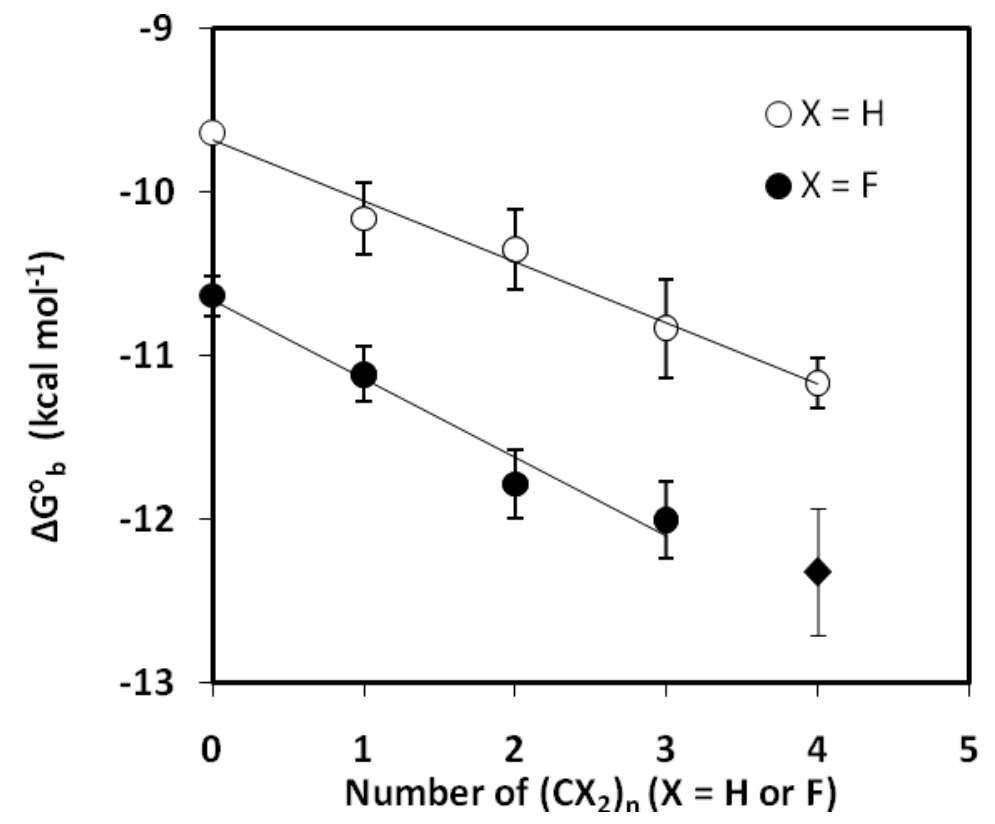

b)

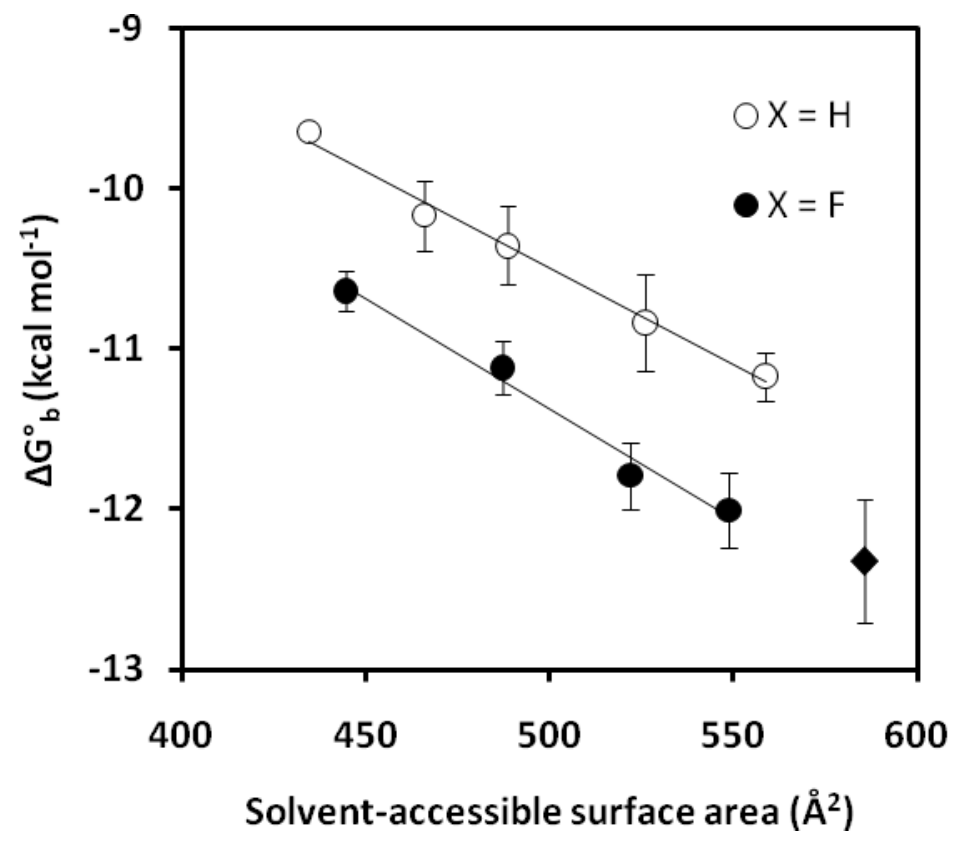

Figure 2. a) Dependence of $\Delta G_{b}^{\circ}$ for binding of benzenesulfonamide ligands $\left(\mathrm{H}_{2} \mathrm{NSO}_{2} \mathrm{C}_{6} \mathrm{H}_{4}-\right.$ $\left.\mathrm{CONHCH}_{2}\left(\mathrm{CX}_{2}\right)_{\mathrm{n}} \mathrm{CX}_{3}, \mathrm{X}=\mathrm{H}, \mathrm{F}\right)$ with alkyl (०) and fluoroalkyl (•) tails on their chain length. The slope of the regression line through the alkyl data is $\Delta \Delta G_{\mathrm{b}}^{\circ}=-366 \pm 30 \mathrm{cal} \mathrm{mol}^{-1}-\mathrm{CH}_{2^{-}}{ }^{-1}$, and that for fluoroalkyl data is $\Delta \Delta G^{\circ}{ }_{\mathrm{b}}=-479 \pm 35 \mathrm{cal} \mathrm{mol}^{-1}-\mathrm{CF}_{2^{-}}{ }^{-1}(\mathrm{~N}=7)$. b) Dependence of $\Delta G^{\circ}$ for binding of 
benzenesulfonamide ligands with alkyl (०) and fluoroalkyl (•) tails on their solvent-accessible surface area in the fully extended conformation. The slope of the regression line for the alkyl data is $\Delta \Delta G^{\circ}{ }_{\mathrm{b}}=$ $-12 \pm 1 \mathrm{cal} \mathrm{mol}^{-1} \AA^{-2}$, and that for the fluoroalkyl data is $\Delta \Delta G_{\mathrm{b}}^{\circ}=-14 \pm 1 \mathrm{cal} \mathrm{mol}^{-1} \AA^{-2}(\mathrm{~N}=7)$. The longest fluoroalkyl ligand ( $\bullet$ is not included in the linear regression, because, in contrast to other fluoroalkyl ligands, it causes a flip in the orientation of Gln136 of HCA II (see the text). 
a)

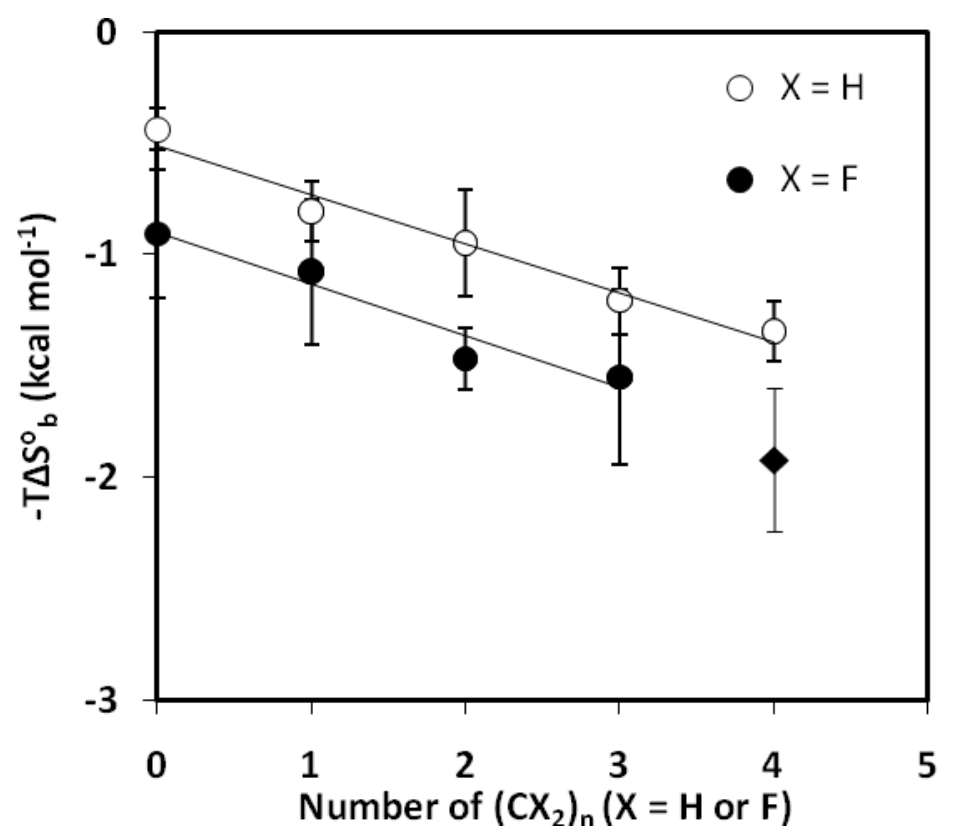

b)

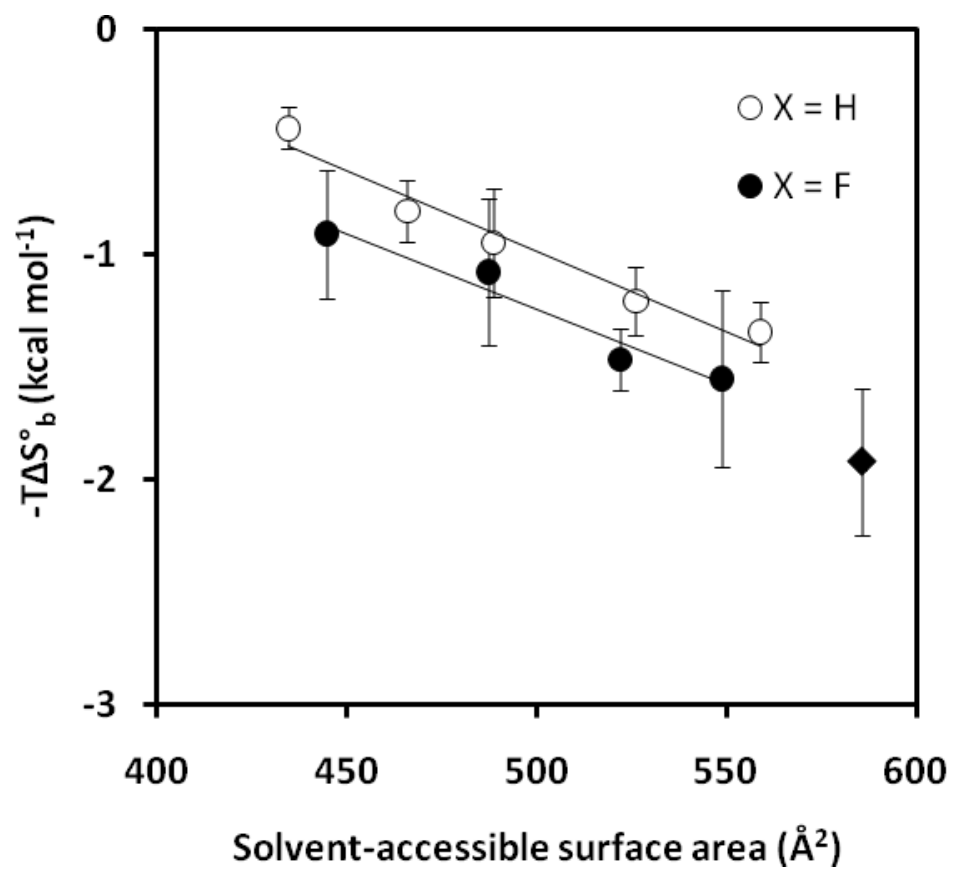

Figure 3. a) Plots for $-\mathrm{T} \Delta S_{\mathrm{b}}^{\circ}$ versus chain length for alkyl (०) and fluoroalkyl (•) tails of benzensulfonamide ligands $\left(\mathrm{H}_{2} \mathrm{NSO}_{2} \mathrm{C}_{6} \mathrm{H}_{4}-\mathrm{CONHCH}_{2}\left(\mathrm{CX}_{2}\right)_{n} \mathrm{CX}_{3}, \mathrm{X}=\mathrm{H}, \mathrm{F}\right)$. The slope of the regression line through the alkyl data is $-\mathrm{T} \Delta \Delta S_{\mathrm{b}}^{\circ}=-217 \pm 23 \mathrm{cal} \mathrm{mol}^{-1}-\mathrm{CH}_{2}{ }^{-1}$, and that for fluoroalkyl data is $-\mathrm{T} \Delta \Delta S_{\mathrm{b}}^{\circ}=-232 \pm 48 \mathrm{cal} \mathrm{mol}^{-1}-\mathrm{CF}_{2^{-}}{ }^{-1}(\mathrm{~N}=7)$. b) Plots for $-\mathrm{T} \Delta S_{\mathrm{b}}^{\circ}$ versus solvent-accessible surface area for alkyl (०) and fluoroalkyl (•) tails. The slope of the regression line for the alkyl data is - 
$\mathrm{T} \Delta \Delta S_{\mathrm{b}}^{\circ}=-7 \pm 1 \mathrm{cal} \mathrm{mol}^{-1} \AA^{-2}$, and that for the fluoroalkyl data is $-\mathrm{T} \Delta \Delta S_{\mathrm{b}}^{\circ}=-7 \pm 1 \mathrm{cal} \mathrm{mol}^{-1} \AA^{-2}(\mathrm{~N}=$ 7). The longest fluoroalkyl ligand ( $\bullet$ is not included in the trendline, because it causes the conformational change of Gln136 of HCA II (see the text). 
a)

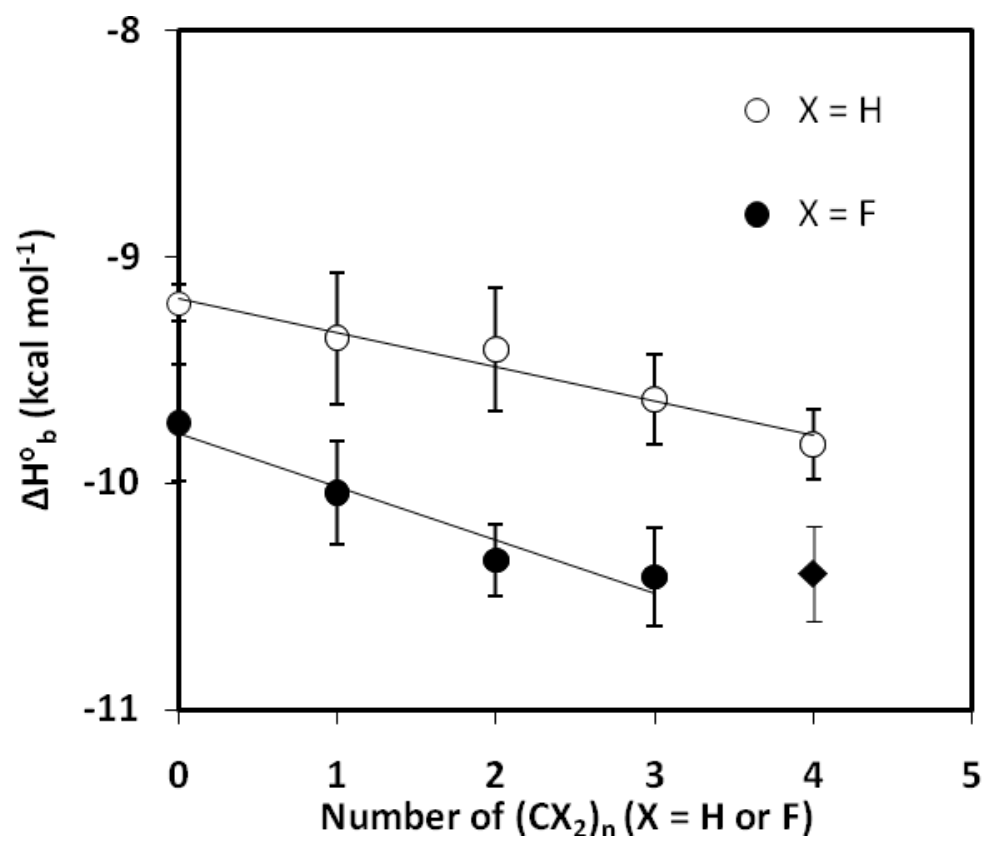

b)

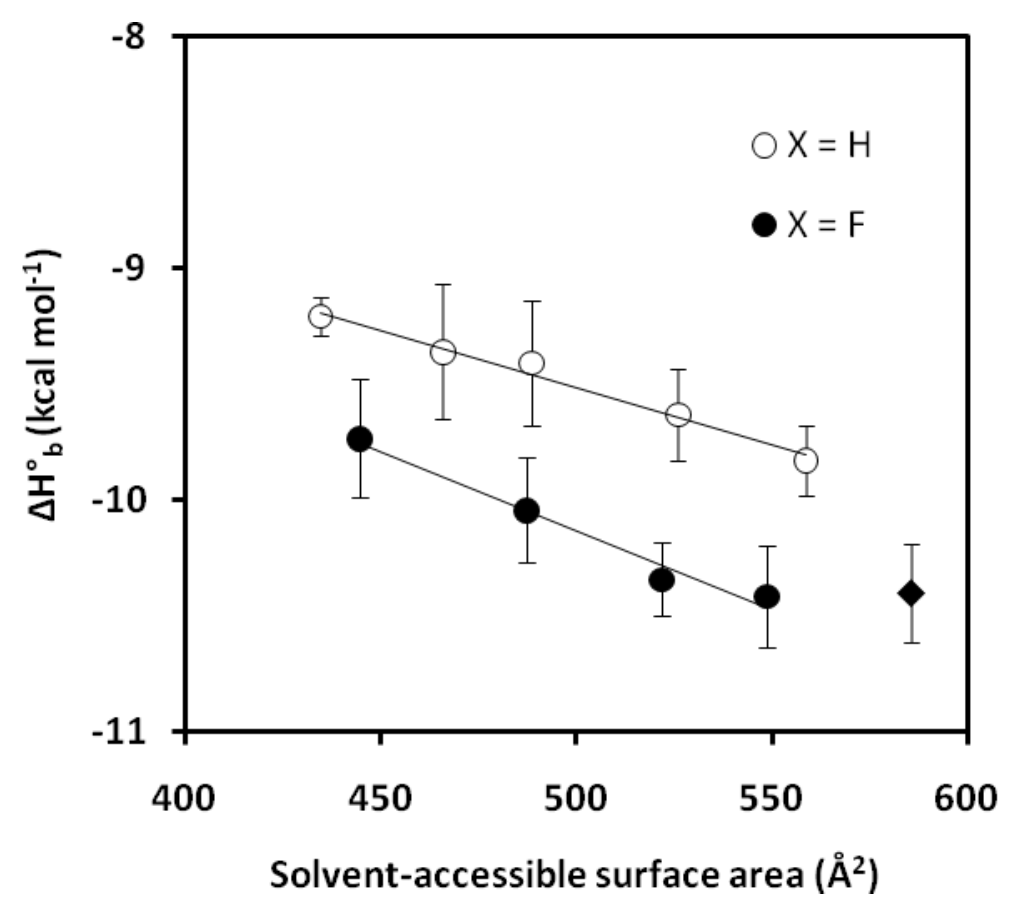

Figure 4. a) Dependence of $\Delta H_{b}^{\circ}$ for benzenesulfonamide ligands $\left(\mathrm{H}_{2} \mathrm{NSO}_{2} \mathrm{C}_{6} \mathrm{H}_{4}-\right.$ $\left.\mathrm{CONHCH}_{2}\left(\mathrm{CX}_{2}\right)_{\mathrm{n}} \mathrm{CX}_{3}, \mathrm{X}=\mathrm{H}, \mathrm{F}\right)$ containing alkyl (०) and fluoroalkyl $(\bullet)$ tails on the length of the chain. The slope of the regression line through the alkyl data is $\Delta \Delta H_{\mathrm{b}}^{\circ}=-150 \pm 30 \mathrm{cal} \mathrm{mol}^{-1}-\mathrm{CH}_{2^{-}}{ }^{-1}$, and that for fluoroalkyl data is $\Delta \Delta H^{\circ}{ }_{\mathrm{b}}=-247 \pm 37 \mathrm{cal} \mathrm{mol}^{-1}-\mathrm{CF}_{2^{-}}{ }^{-1}(\mathrm{~N}=7)$. b) Dependence of $\Delta H^{\circ}$ for 
ligands containing alkyl $(\circ)$ and fluoroalkyl $(\bullet)$ tails on the solvent-accessible surface area. The slope of the regression line for the alkyl data is $\Delta \Delta H^{\circ}{ }_{\mathrm{b}}=-5 \pm 1 \mathrm{cal} \mathrm{mol}^{-1} \AA^{-2}$, and that for the fluoroalkyl data is $\Delta \Delta H^{\circ}{ }_{\mathrm{b}}=-7 \pm 1 \mathrm{cal} \mathrm{mol}^{-1} \AA^{-2}(\mathrm{~N}=7)$. The longest fluoroalkyl ligand $(\diamond)$ is not included in the trendline, because it causes the conformational change of Gln136 of HCA II (see the text). 

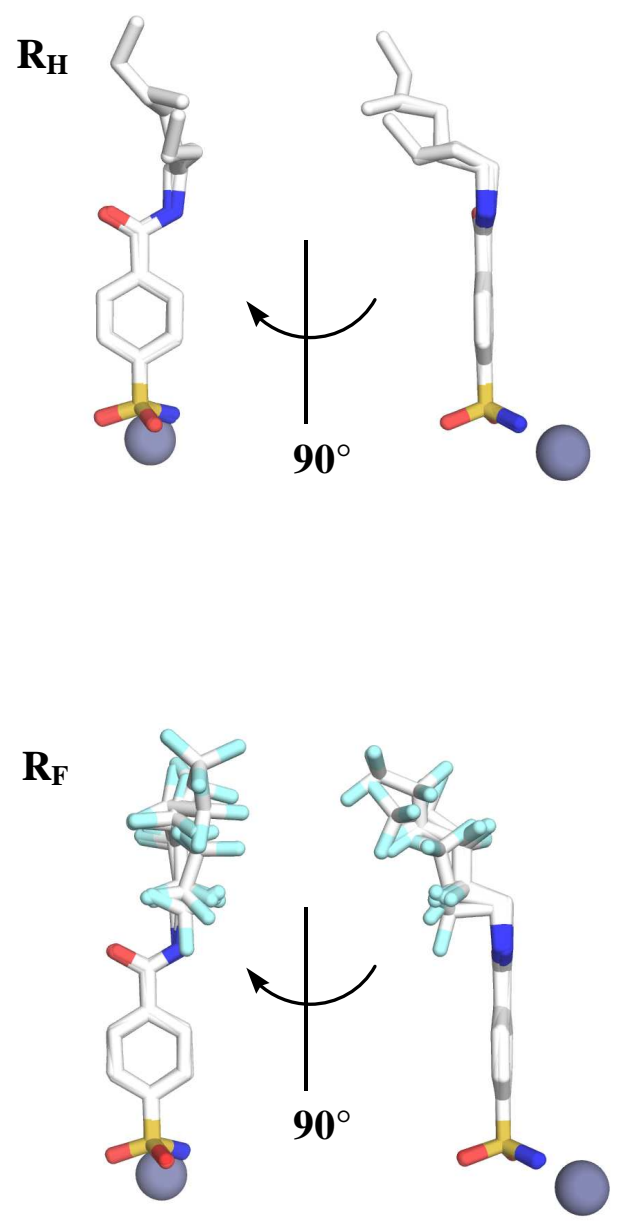

Figure 5. Alignment of the atoms of the ligands. A) Aligned structures for ten ligands determined by $\mathrm{X}$-ray crystallography appear as ball and stick representations. The $\mathrm{Zn}^{2+}$ cofactor appears as a silver sphere. Individual images of each ligand appear in Figure S6 in Supporting Information. 

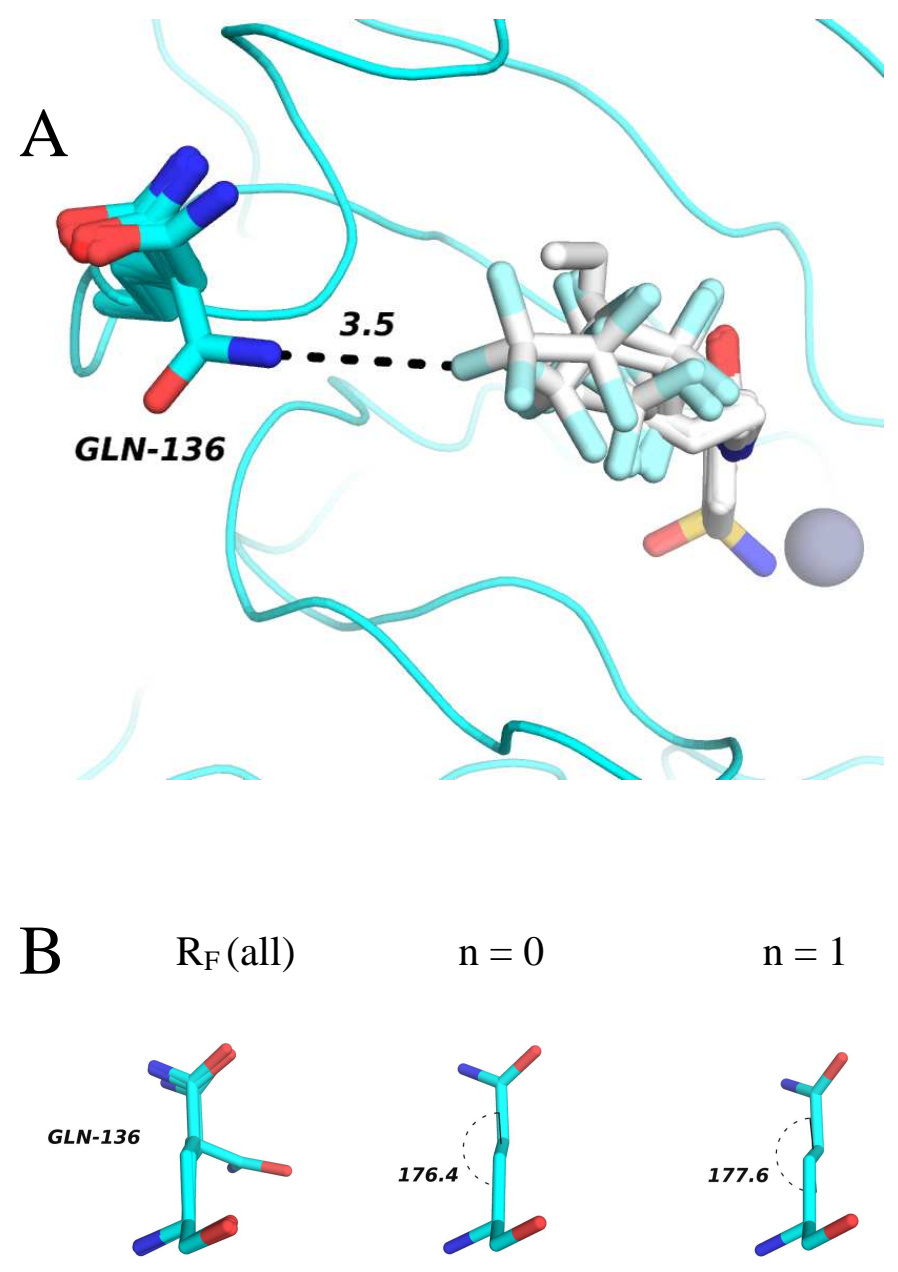

$$
\mathrm{n}=2
$$

$$
\mathrm{n}=3
$$

$$
\mathrm{n}=4
$$
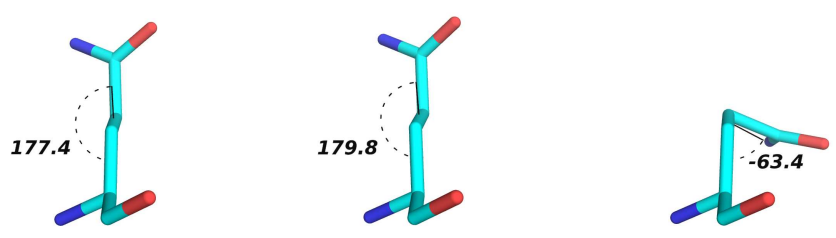

Figure 6. Crystal structures of fluorinated 'greasy tails' complexed with HCA II. A) Superimposition of all ligands and the Gln136 side chain. The distance between Gln136 and one fluorine atom of the ligand $\left(\mathrm{R}_{\mathrm{F}}, \mathrm{n}=4\right)$ appears as a dashed line with its length labeled in $\AA$. B) Conformational analysis for Gln136. Superimposition of ligands (top left) and individual ligands. Gln136 possesses the anti conformation in cases of $n=0-3$, while the gauche conformation is observed in the case of $n=4$. Values of dihedral angles are labeled. 
Table 1. Comparison of the dependence of the $\Delta G^{\circ}, \Delta H^{\circ}{ }_{\mathrm{b}}$ and $-\mathrm{T} \Delta S^{\circ}{ }_{\mathrm{b}}$ on the chain length (n), ligand surface area (A), ligand solvent-accessible surface area (SASA), and volume of the ligand (V) for alkyl $(\mathrm{X}=\mathrm{H})$ and fluoroalkyl $(\mathrm{X}=\mathrm{F})$ tails of $\mathrm{H}_{2} \mathrm{NSO}_{2} \mathrm{C}_{6} \mathrm{H}_{4} \mathrm{CONHCH}_{2}\left(\mathrm{CX}_{2}\right)_{\mathrm{n}} \mathrm{CX}_{3}(\mathrm{n}=0-4)$ to HCA II.

\begin{tabular}{lcc}
\hline & Hydrocarbon, $\mathrm{R}_{\mathrm{H}}$ & Fluorocarbon, $\mathrm{R}_{\mathrm{F}}$ \\
\hline$\Delta \Delta \mathrm{G}_{\mathrm{o}} / \Delta \mathrm{n}^{\mathrm{a}}\left(\mathrm{cal} \mathrm{mol}^{-1}\right)$ & $-366 \pm 30$ & $-479 \pm 35$ \\
$\Delta \Delta \mathrm{G}^{\circ} / \Delta \mathrm{A}^{\mathrm{b}}\left(\mathrm{cal} \mathrm{mol}^{-1} \AA^{-2}\right)$ & $-18 \pm 1$ & $-18 \pm 1$ \\
$\Delta \Delta \mathrm{G}^{\circ} / \Delta \mathrm{SASA}^{\mathrm{c}}\left(\mathrm{cal} \mathrm{mol}^{-1} \AA^{-2}\right)$ & $-12 \pm 1$ & $-14 \pm 1$ \\
$\Delta \Delta \mathrm{G}^{\circ}{ }_{b} / \Delta \mathrm{V}^{\mathrm{d}}\left(\mathrm{cal} \mathrm{mol}^{-1} \AA^{-3}\right)$ & $-20 \pm 2$ & $-20 \pm 2$ \\
\hline$\Delta \Delta H^{\circ}{ }_{b} / \Delta \mathrm{n}^{\mathrm{a}}\left(\mathrm{cal} \mathrm{mol}^{-1}\right)$ & $-150 \pm 30$ & $-247 \pm 37$ \\
$\Delta \Delta H^{\circ}{ }_{b} / \Delta \mathrm{A}^{\mathrm{b}}\left(\mathrm{cal} \mathrm{mol}^{-1} \AA^{-2}\right)$ & $-7 \pm 1$ & $-9 \pm 1$ \\
$\Delta \Delta H^{\circ}{ }_{b} / \Delta \mathrm{SASA}^{\mathrm{c}}\left(\mathrm{cal} \mathrm{mol}^{-1} \AA^{-2}\right)$ & $-5 \pm 1$ & $-7 \pm 1$ \\
$\Delta \Delta H^{\circ}{ }_{b} / \Delta \mathrm{V}^{\mathrm{d}}\left(\mathrm{cal} \mathrm{mol}^{-1} \AA^{-3}\right)$ & $-8 \pm 2$ & $-10 \pm 2$ \\
\hline$-\mathrm{T} \Delta \Delta S^{\circ}{ }_{b} / \Delta \mathrm{n}^{\mathrm{a}}\left(\mathrm{cal} \mathrm{mol}^{-1}\right)$ & $-216 \pm 23$ & $-232 \pm 48$ \\
$-\mathrm{T} \Delta \Delta S^{\circ}{ }_{b} / \Delta \mathrm{A}^{\mathrm{b}}\left(\mathrm{cal} \mathrm{mol}^{-1} \AA^{-2}\right)$ & $-11 \pm 1$ & $-9 \pm 2$ \\
$-\mathrm{T} \Delta \Delta S^{\circ}{ }_{b} / \Delta \mathrm{SASA}^{\mathrm{c}}\left(\mathrm{cal} \mathrm{mol}^{-1} \AA^{-2}\right)$ & $-7 \pm 1$ & $-7 \pm 1$ \\
$-\mathrm{T} \Delta \Delta S^{\circ}{ }_{b} / \Delta \mathrm{V}^{\mathrm{d}}\left(\mathrm{cal} \mathrm{mol}^{-1} \AA^{-3}\right)$ & $-12 \pm 1$ & $-10 \pm 2$ \\
\hline
\end{tabular}

a Obtained from the slope of $\Delta G^{\circ}{ }_{b}, \Delta H^{\circ} \mathrm{b}$ or $-\mathrm{T} \Delta S^{\circ} \mathrm{b}$ vs. the number of carbon atoms of the tail (Figures 2-4). ${ }^{\mathrm{b}}$ Obtained from the slope of $\Delta G^{\circ}, \Delta H^{\circ} \mathrm{b}$ or $-\mathrm{T} \Delta S^{\circ} \mathrm{b}$ vs. the surface area (A) of the tail in the fully extended conformation (Figures S1-S3 in Supporting Information). ${ }^{\mathrm{c}}$ Obtained from the slope of $\Delta G^{\circ} \mathrm{b}, \Delta H^{\circ} \mathrm{b}$ or $-\mathrm{T} \Delta S^{\circ} \mathrm{b}$ vs. the solvent-accessible surface area (SASA) of the tail in the fully extended conformation (Figures 2-4). ${ }^{d}$ Obtained from the slope of $\Delta G^{\circ} \mathrm{b}, \Delta H^{\circ} \mathrm{b}$ or $-\mathrm{T} \Delta S^{\circ} \mathrm{b}$ vs. the volume $(\mathrm{V})$ of the tail in the fully extended conformation (Figures S1-S3). 
Table 2. Thermodynamic parameters $\Delta G^{\circ}, \Delta H_{\mathrm{b}}^{\circ},-\mathrm{T} \Delta S_{\mathrm{b}}^{\circ}$ for binding of inhibitors $\left(\mathrm{H}_{2} \mathrm{NSO}_{2} \mathrm{C}_{6} \mathrm{H}_{4}-\right.$ $\left.\mathrm{CONHCH}_{2}\left(\mathrm{CX}_{2}\right)_{\mathrm{n}} \mathrm{CX}_{3}, \mathrm{n}=0-4, \mathrm{X}=\mathrm{H}, \mathrm{F}\right)$ to HCA II. The solvent-accessible surface area (SASA) of ligands was calculated using the Molecular Operating Environment (MOE) suite.

\begin{tabular}{cccccccc}
\hline $\mathrm{N}$ & $\mathrm{X}$ & $\begin{array}{c}\mathrm{SASA} \\
\left(\AA^{2}\right)\end{array}$ & $\begin{array}{c}K_{\mathrm{d}} \\
(\mathrm{nM})\end{array}$ & $\begin{array}{c}\Delta G^{\circ} \mathrm{b} \\
(\mathrm{kcal} / \mathrm{mol})\end{array}$ & $\begin{array}{c}\Delta H_{\mathrm{b}}^{\circ} \\
(\mathrm{kcal} / \mathrm{mol})\end{array}$ & $\begin{array}{c}-\mathrm{T} \Delta S_{\mathrm{b}}^{\circ} \\
(\mathrm{kcal} / \mathrm{mol})\end{array}$ & $\begin{array}{c}\mathrm{PDB} \\
\mathrm{ID}\end{array}$ \\
\hline 0 & $\mathrm{H}$ & 239 & 86 & -9.6 & -9.2 & -0.4 & \\
1 & $\mathrm{H}$ & 261 & 38 & -10.2 & -9.4 & -0.8 \\
2 & $\mathrm{H}$ & 280 & 28 & -10.4 & -9.4 & -1.0 \\
3 & $\mathrm{H}$ & 303 & 13 & -10.8 & -9.6 & -1.2 \\
4 & $\mathrm{H}$ & 323 & 6.7 & -11.2 & -9.8 & -1.3 \\
0 & $\mathrm{~F}$ & 243 & 16 & -10.6 & -9.7 & -0.9 \\
1 & $\mathrm{~F}$ & 269 & 7.3 & -11.1 & -10.0 & -1.1 \\
2 & $\mathrm{~F}$ & 295 & 2.4 & -11.8 & -10.3 & -1.5 \\
3 & $\mathrm{~F}$ & 321 & 1.8 & -12.0 & -10.5 & -1.6 & \\
4 & $\mathrm{~F}$ & 347 & 1.1 & -12.3 & -10.4 & -1.9 \\
\hline
\end{tabular}




\section{REFERENCES}

(1) Kauzmann, W. Adv. Protein Chem. 1959, 14, 1.

(2) Tanford, C. Science 1978, 200, 1012.

(3) Tanford, C. J. Mol. Bio. 1972, 67, 59.

(4) Southall, N. T.; Dill, K. A.; Haymet, A. D. J. J. Phys. Chem. B 2001, 106, 521.

(5) Ball, P. Chem. Rev. 2008, 108, 74.

(6) Southall, N. T.; Dill, K. A.; Haymet, A. D. J. J. Phys. Chem. B 2002, 106, 521.

(7) Blokzijl, W.; Engberts, J. B. F. N. Angew. Chem. Int. Ed. 1993, 32, 1545.

(8) Dalvi, V. H.; Rossky, P. J. Proc. Natl. Acad. Sci. USA 2010, 107, 13603.

(9) Muller, K.; Faeh, C.; Diederich, F. Science 2007, 317, 1881.

(10) Montclare, J. K.; Son, S.; Clark, G. A.; Kumar, K.; Tirrell, D. A. ChemBioChem 2009, 10,84 .

(11) Yoder, N. C.; Kumar, K. Chem. Soc. Rev. 2002, 31, 335.

(12) Gao, J.; Qiao, S.; Whitesides, G. M. J. Med. Chem. 1995, 38, 2292.

(13) Lee, A.; Mirica, K. A.; Whitesides, G. M. J. Phys. Chem. B 2011, 115, 1199.

(14) Dunitz, J. D. ChemBioChem 2004, 5, 614.

(15) Krishnamurthy, V. M.; Kaufman, G. K.; Urbach, A. R.; Gitlin, I.; Gudiksen, K. L.; Weibel, D. B.; Whitesides, G. M. Chem. Rev. 2008, 108, 946.

(16) Krishnamurthy, V.; Bohall, B.; Kim, C. Y.; Moustakas, D.; Christianson, D.; Whitesides, G. Chem. Asian J. 2007, 2, 94.

(17) Böhm, H.-J.; Banner, D.; Bendels, S.; Kansy, M.; Kuhn, B.; Müller, K.; Obst-Sander, U.; Stahl, M. ChemBioChem 2004, 5, 637.

(18) Kwon, O.-H.; Yoo, T. H.; Othon, C. M.; Van Deventer, J. A.; Tirrell, D. A.; Zewail, A. H. Proc. Natl. Acad. Sci. USA 2010, 107, 17101.

(19) Biffinger, J. C.; Kim, H. W.; DiMagno, S. G. ChemBioChem 2004, 5, 622.

(20) Frank, H. S.; Evans, M. W. J. Chem. Phys. 1945, 13, 507.

(21) Jeffrey, G. A. Acc. Chem. Res. 1969, 2, 344.

(22) Tanford, C. The Hydrophobic Effect: Formation of Micelles and Biological Membranes; John Wiley \& Sons Inc.: New York, 1973.

(23) Brown, M. G.; Walker, D. S.; Raymond, E. A.; Richmond, G. L. J. Phys. Chem. B 2003, 107, 237.

(24) Richmond, G. L. Ann. Rev. Phys. Chem. 2001, 52, 357. 
(25) Du, Q.; Superfine, R.; Freysz, E.; Shen, Y. R. Phys. Rev. Lett. 1993, 70, 2313.

(26) Ji, N.; Ostroverkhov, V.; Tian, C. S.; Shen, Y. R. Phys. Rev. Lett. 2008, 100, 096102.

(27) Buchanan, P.; Aldiwan, N.; Soper, A. K.; Creek, J. L.; Koh, C. A. Chem. Phys. Lett. 2005, 415, 89 .

(28) Soper, A. K.; Bruni, F.; Ricci, M. A. J. Chem. Phys. 1998, 109, 1486.

(29) Stillinger, F. H. J. Sol. Chem. 1973, 2, 141.

(30) Pratt, L. R.; Pohorille, A. Chem. Rev. 2002, 102, 2671.

(31) Lum, K.; Chandler, D.; Weeks, J. D. J. Phys. Chem. B 1999, 103, 4570.

(32) Chandler, D. Nature 2005, 437, 640.

(33) Rossky, P. J.; Karplus, M. J. Am. Chem. Soc. 1979, 101, 1913.

(34) Dill, K. A.; Truskett, T. M.; Vlachy, V.; Hribar-Lee, B. Ann. Rev. Biophys. Biomol. Struct. 2005, 34, 173.

(35) Raschke, T. M.; Levitt, M. Proc. Natl. Acad. Sci. U.S.A. 2005, 102, 6777.

(36) Cheng, Y.-K.; Rossky, P. J. Nature 1998, 392, 696.

(37) Giovambattista, N.; Lopez, C. F.; Rossky, P. J.; Debenedetti, P. G. Proc. Natl. Acad. Sci. USA 2008, 105, 2274.

(38) Berne, B. J.; Weeks, J. D.; Zhou, R. Ann. Rev. Phys. Chem. 2009, 60, 85.

(39) Liu, P.; Huang, X.; Zhou, R.; Berne, B. J. Nature 2005, 437, 159.

(40) Wang, L.; Berne, B. J.; Friesner, R. A. Proc. Natl. Acad. Sci. USA 2011, 108, 1326.

(41) Young, T.; Abel, R.; Kim, B.; Berne, B. J.; Friesner, R. A. Proc. Natl. Acad. Sci. USA 2007, 104, 808 .

(42) Zhou, R.; Huang, X.; Margulis, C. J.; Berne, B. J. Science 2004, 305, 1605.

(43) Abel, R.; Salam, N. K.; Shelley, J.; Farid, R.; Friesner, R. A.; Sherman, W. ChemMedChem 2011, n/a.

(44) Lemieux, R. U. Acc. Chem. Res. 1996, 29, 373.

(45) Connelly, P. R. Structure-Based Drug Design: Thermodynamics, Modeling and Strategy; Springer: Berlin, 1997.

(46) Chervenak, M. C.; Toone, E. J. J. Am. Chem. Soc. 1994, 116, 10533.

(47) Williams, B. A.; Chervenak, M. C.; Toone, E. J. J. Biol. Chem. 1992, 267, 22907.

(48) Ladbury, J. E.; Wright, J. G.; Sturtevant, J. M.; Sigler, P. B. J. Mol. Bio. 1994, 238, 669.

(49) Olsson, T. S. G.; Williams, M. A.; Pitt, W. R.; Ladbury, J. E. J. Mol. Bio. 2008, 384, 1002 .

(50) Homans, S. W. Drug. Discov. Today 2007, 12, 534. 
(51) Malham, R.; Johnstone, S.; Bingham, R. J.; Barratt, E.; Phillips, S. E. V.; Laughton, C. A.; Homans, S. W. J. Am. Chem. Soc. 2005, 127, 17061.

(52) Wiseman, T.; Williston, S.; Brandts, J. F.; Lin, L.-N. Anal. Biochem. 1989, 179, 131.

(53) Boriack-Sjodin, P. A.; Zeitlin, S.; Christianson, D. W.; Chen, H.-H.; Crenshaw, L.; Gross, S.; Dantanarayana, A.; Delgado, P.; May, J. A.; Dean, T. Prot. Sci. 1998, 7, 2483.

(54) Nair, S. K.; Calderone, T. L.; Christianson, D. W.; Fierke, C. A. J. Biol. Chem. 1991, $266,17320$.

(55) Burton, R. E.; Oas, T. G.; Fierke, C. A.; Hunt, J. A. Prot. Sci. 2000, 9, 776.

(56) Khalifah, R. G.; Strader, D. J.; Bryant, S. H.; Gibson, S. M. Biochemistry 1977, 16, 2241.

(57) Turnbull, W. B.; Daranas, A. H. J. Am. Chem. Soc. 2003, 125, 14859.

(58) Plyasunov, A. V.; Shock, E. L. Geochim. Cosmochim. Acta 2000, 64, 439.

(59) Krishnamurthy, V. M.; Bohall, B. R.; Semetey, V.; Whitesides, G. M. J. Am. Chem. Soc. 2006, 128,5802 .

\section{SYNOPSIS TOC}
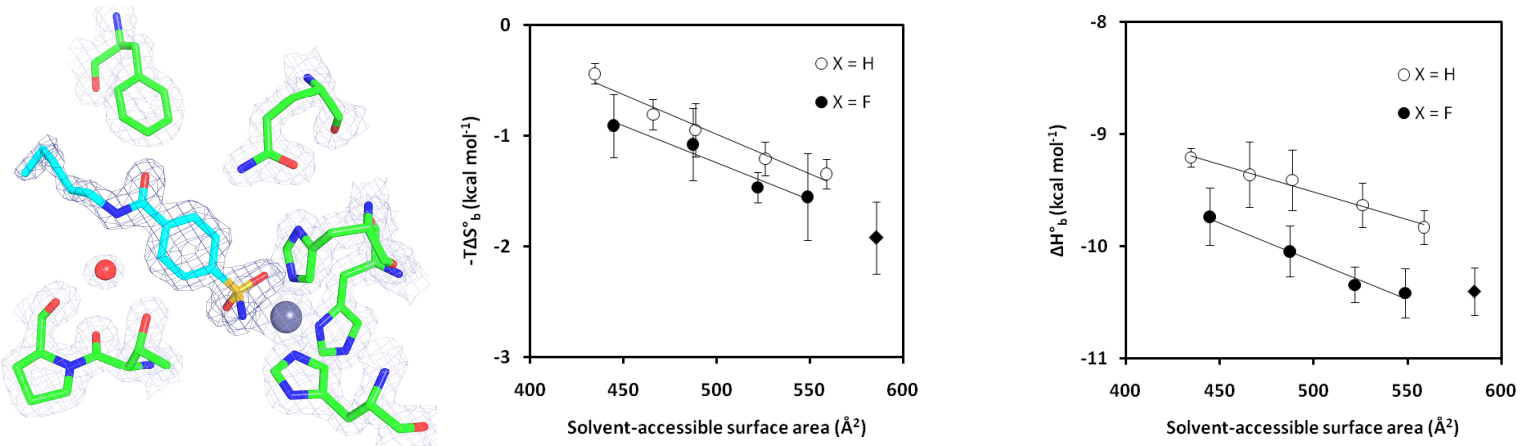